\title{
Archéopages
}

Archéopages

Archéologie et société

42 | 04-07/2015

Construire en terre crue

\section{La construction en terre crue au Néolithique}

Un état de la question en France

Building with earth in the Neolithic in France: an overview

La construcción en barro durante el Neolítico: en Francia

Ingrid Sénépart, Julia Wattez, Luc Jallot, Tony Hamon et Marylise Onfray

\section{OpenEdition}

\section{Journals}

Édition électronique

URL : https://journals.openedition.org/archeopages/1106

DOI : 10.4000/archeopages. 1106

ISSN : 2269-9872

Éditeur

INRAP - Institut national de recherches archéologiques préventives

Édition imprimée

Date de publication : 1 mars 2016

Pagination : 6-19

ISSN : 1622-8545

Référence électronique

Ingrid Sénépart, Julia Wattez, Luc Jallot, Tony Hamon et Marylise Onfray, «La construction en terre crue au Néolithique », Archéopages [En ligne], 42 | 04-07/2015, mis en ligne le 01 juillet 2017, consulté le 02 juin 2021. URL : http://journals.openedition.org/archeopages/1106 ; DOI : https://doi.org/ 10.4000/archeopages.1106 


\section{La construction en terre crue au Néolithique Un état de la question en France}

Ingrid Sénépart Ville de Marseille, UMR 7264, «CEPAM "

Julia Wattez Inrap, UMR 5140, «Archéologie des Sociétés Méditerraneénnes"

LuC Jallot université Montpellier 3, UMR 5140, «Archéologie des Sociétés Méditerranéennes»

Tony Hamon Inrap, UMR 8215 , «Trajectoires»

Marylise Onfray uMR 8215 , «Trajectoires»

En France, pendant longtemps, l'usage de la terre dans l'architecture néolithique a été uniquement attesté par des débris de torchis. Ces fragments, souvent brûlés, incrustés d'empreintes de clayonnage, signalent, dès le Néolithique ancien, la présence de bâtiments à ossature de bois, remplie par un mélange de terre et de végétaux. Or, depuis une vingtaine d'années, les recherches menées dans le cadre d'opérations préventives et programmées dans le sud de la France, puis dans le nord, ont conduit à réviser ce constat. Elles ont montré en effet que la terre crue est aussi employée dans la construction de murs où elle assume un rôle porteur, et dans l'aménagement de sols d'habitat, dès le Néolithique ancien (Jallot, 2003 ; Sénépart, 2000 et 2009 ; Wattez, 2003). À partir du Néolithique moyen, son usage est récurrent, des rives de la Méditerranée au littoral de la Manche. Les premières découvertes en Provence et en Languedoc, dès les années 1990, ont ainsi modifié le schéma d'apparition des techniques constructives en terre crue, jusque-là attribuées au Bronze final (Billaud, 2005 ; Chazelles, 2007 ; Jallot, 2003 ; Wattez, 2003).

Néanmoins, la détection et la fouille de ces vestiges ne vont pas de soi. Même dans les tells proche-orientaux où la construction en terre crue est pourtant un fait, son dégagement reste un exercice difficile (Goldberg et Macphail, 2006). Les recherches menées à partir des années 1980 sur les sites protohistoriques et antiques méridionaux et sur le tell néolithique de Kovačevo, en Bulgarie, montrent que les difficultés de détection dépendent de plusieurs facteurs : la nature des matériaux employés dans la construction, le plus souvent extraits des formations sédimentaires et pédologiques du site ou des sols d'occupation, la méconnaissance des caractéristiques des techniques de construction, la fragilité du matériau terre, dont l'érosion au cours de l'occupation puis après son abandon conduit à la formation de couches " anonymes», souvent analogues à des formations d'origine naturelle ou à des remblais (Chazelles et Poupet, 1985 ; Brochier, 1994).

Suivant une trame diachronique, cet article propose un état de la recherche sur les types de structures de terre crue et sur les techniques constructives du Néolithique français. Le propos s'appuie pour cela sur un partage d'expériences acquises à partir des problèmes soulevés par leur détection et les solutions adoptées pour y remédier.

L'identification et l'interprétation des structures de terre crue néolithiques : une lecture interdisciplinaire

Des vestiges de constructions en terre ont été identifiés dans des sites dont la stratification est parfois indigente ou peu différenciée ou encore dans des structures en creux. Les formes reconnues sont variables, depuis les structures évidentes, comme des segments de murs ou des sols construits, jusqu'aux témoins plus fugaces comme des agrégats, mottes ou boulettes de sédiments distribués dans les couches massives ou non différenciées, dites « anonymes ». Leur identification et leur interprétation sont le fruit d'une réflexion interdisciplinaire, élaborée dès la mise au jour des premières structures dans le Midi et consolidée au fur et à mesure de la découverte de nouveaux vestiges dans le nord de la France. Elle conjugue les méthodes de l'archéologie et de la géoarchéologie, en particulier la micromorphologie des sols.

Au cours de la fouille, la détection repose sur le repérage, en plan et en coupe, d'anomalies sédimentaires (sédiments issus de formations plus anciennes, substrat, concentrations d'éléments 


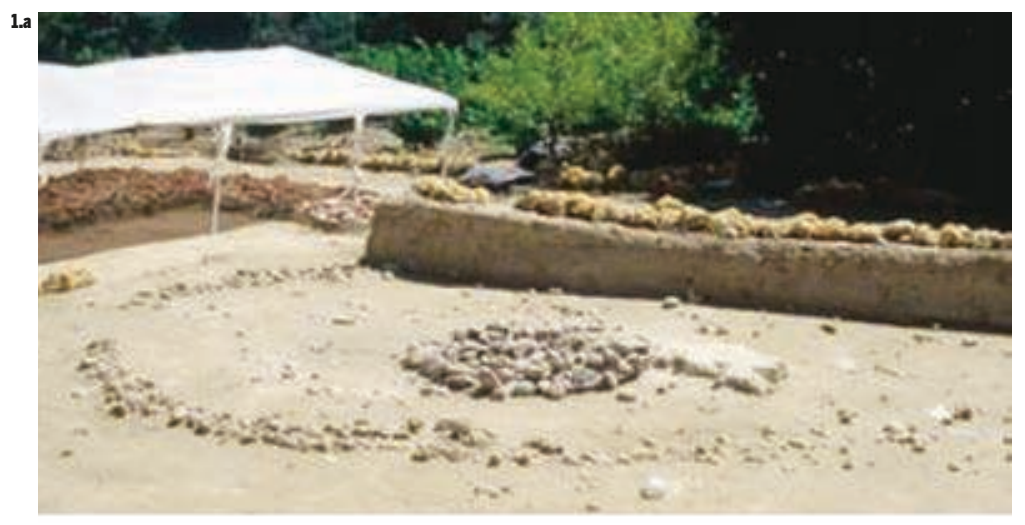

1. Le Baratin à Courthézon

(Vaucluse);

Zone sud - vue générale

de la structure d'habitat;

b. les foyers (ST 8) et leur

sol blanc carbonaté

associé;

c.la dalle de molasse

aménagée et ses sols

blancs;

d. détails des trous de

piquets et des placages et

revêtements carbonatés.
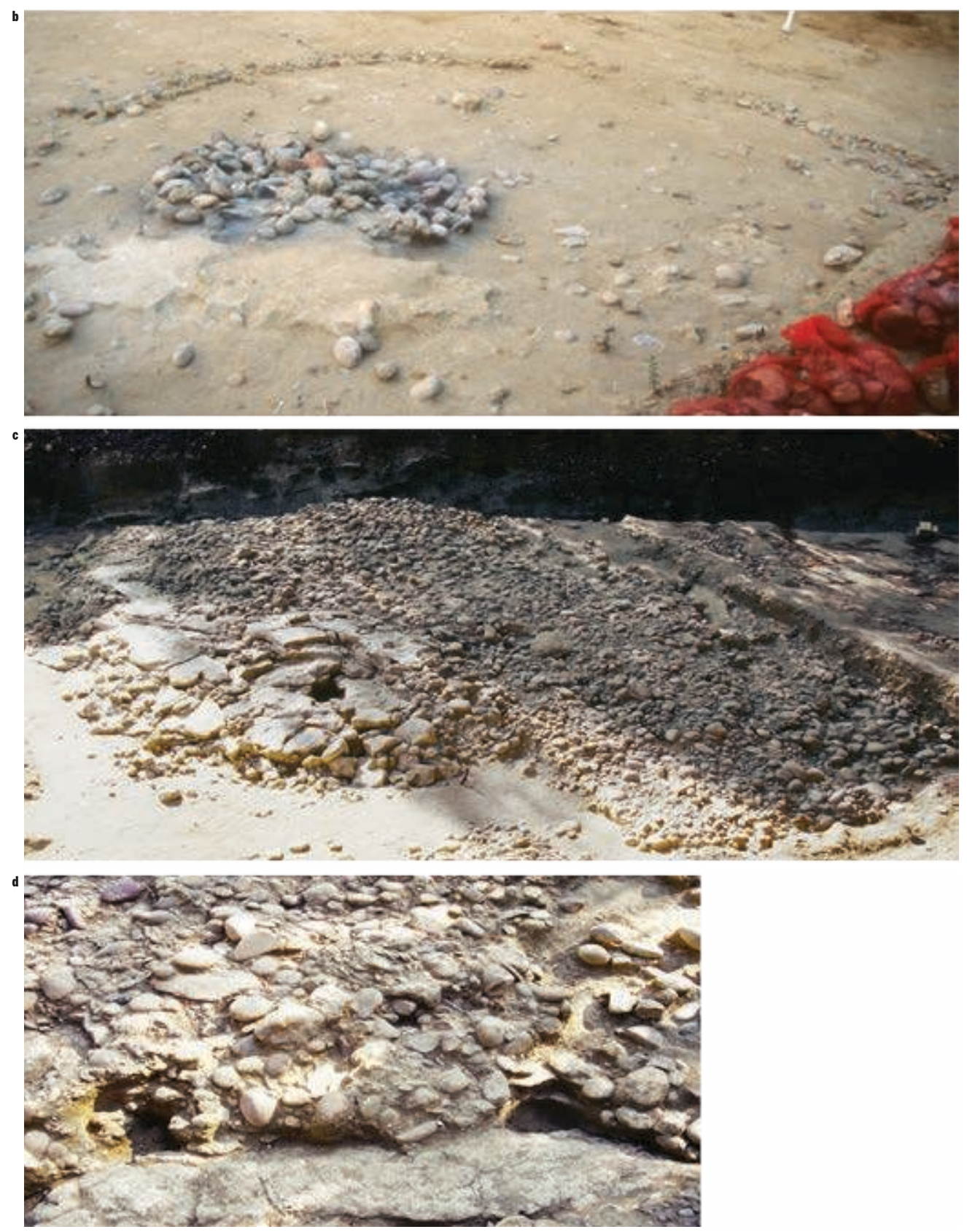


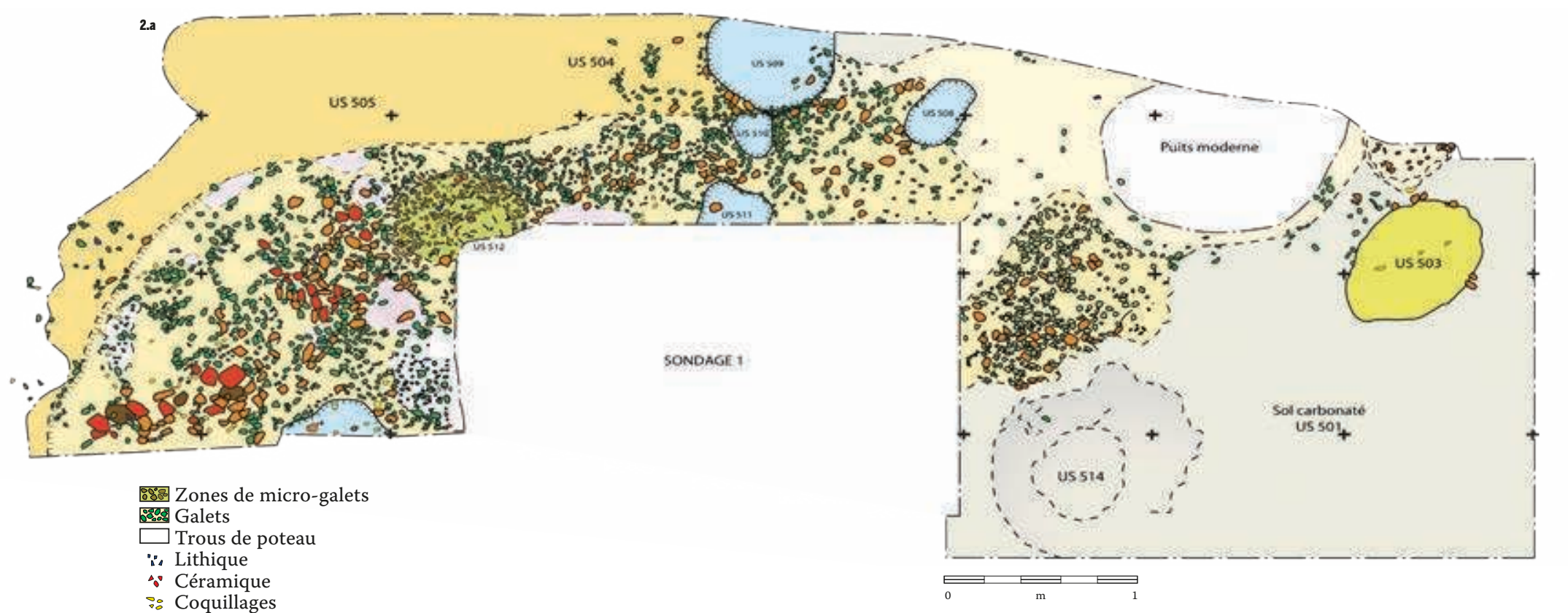

: Coquillages

8 Pierres rubéfiées
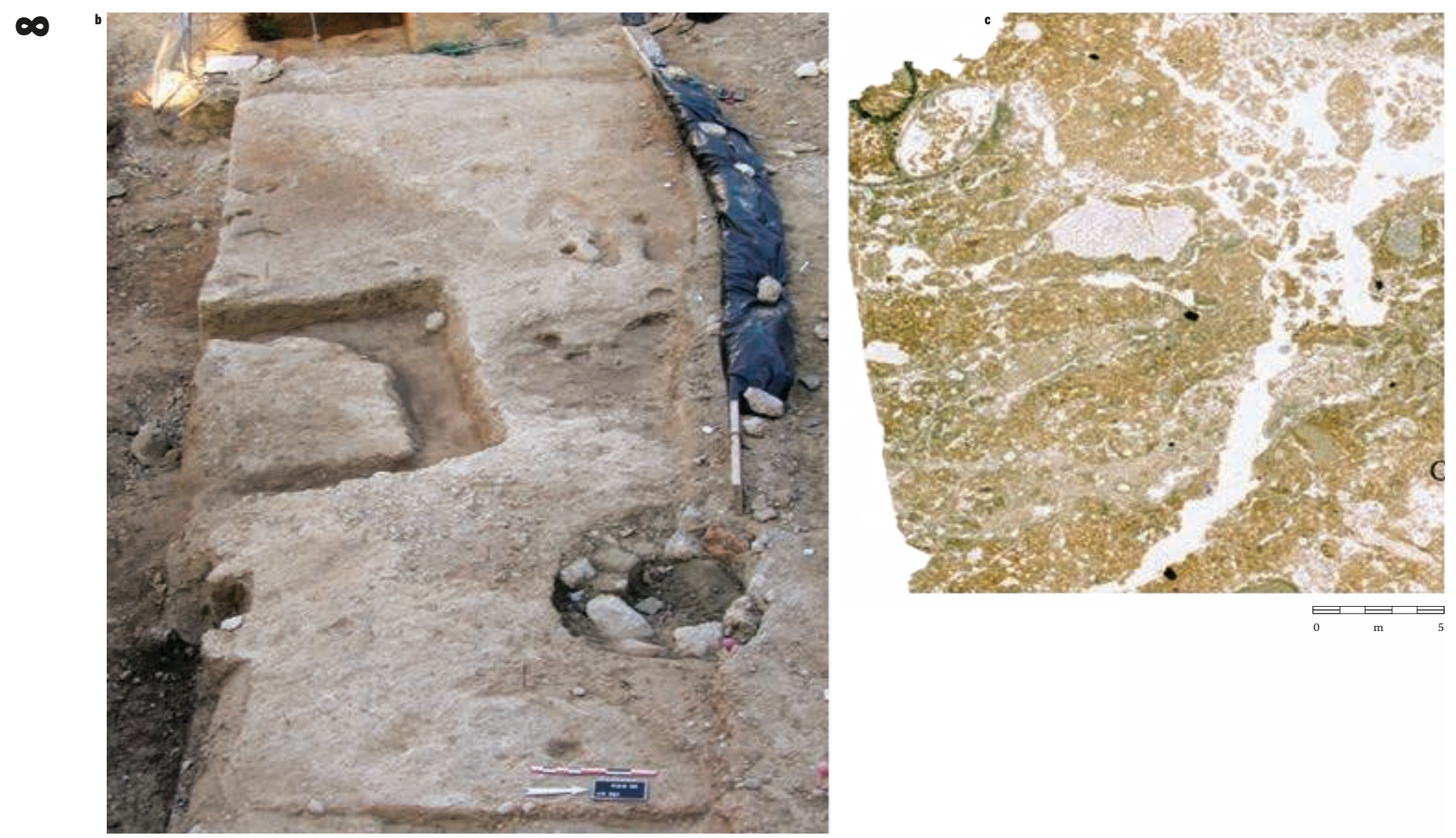

2. Le site de la rue Bernard-

du-Bois à Marseille

(Bouches- du-Rhône)

a. Relevé du niveau

du Néolithique ancien ;

b. Le sol blanc associé

au niveau du Néolithique

ancien ;

c.Microstratigraphie du sol

construit : alternance de

sols faits de limons argileux

avec enduit de boue

calcaire (lentilles claires). 
grossiers ou plus fins, compaction, cimentation ou couleur limitée dans l'eśpace, effets de parois). Elle relève de la méthode des ethno-faciès élaborée pour la lecture des stratifications complexes du tell de Kovačevo (Brochier, 1994). Elle propose une cartographie des anomalies, qui conduit à délimiter des structures latentes, au sens de LeroiGourhan et Brézillon (Leroi-Gourhan et Brézillon, 1972), et à établir les relations stratigraphiques entre les structures évidentes, les sols qui leurs sont associés et leurs couches d'effondrement. L'application de cette méthode a ainsi remarquablement fait ses preuves sur le site de Laprade (Lamotte-du-Rhône, Vaucluse) ${ }^{\mathbf{1}}$, où plusieurs bâtiments en terre du Bronze final ont pu être mis en évidence (Billaud, 2005). Pour caractériser la nature des structures latentes et déterminer l'identité des couches " anonymes », l'étude est prolongée par une analyse microstratigraphique, selon les méthodes de détermination de la micromorphologie des sols (Wattez, 2009).

Par la suite, la compréhension des procédés constructifs repose sur les méthodes conventionnelles de l'archéologie du bâti (relevés, description architecturale, étude du format et de l'assemblage des éléments) puis sur une étude technologique pour préciser la nature et l'origine des matériaux employés, leur mode de préparation, de façonnage et de mise en œuvre. Cette approche s'appuie sur les modèles micromorphologiques établis pour les structures protohistoriques et historiques (Cammas, 2003 ; Roux et Cammas, 2010). Elle est également alimentée par les référentiels proche-orientaux (Stordeur et Wattez, 1998).

Les recherches fondées sur cette lecture interdisciplinaire montrent que le façonnage direct, relevant le plus souvent de la terre massive comme la bauge, était le procédé constructif communément employé au cours du Néolithique (Wattez, 2009; Gutherz et al., 2010 ; Chazelles, 2007). Les matériaux, prélevés sur le site, sont parfois amendés par des ajouts végétaux, par de petits fragments de roche concassée ou par du mobilier. Les études soulignent également qu'à l'instar des tells de milieux arides ou plus tempérés, la stratification, même peu dilatée, résulte très souvent de l'usage de la terre crue (Wattez, 2009; Wattez et Onfray, 2014).

1. Fouille de Laprade,

à La Motte-du-Rhône

(Vaucluse), menée en 1996

sous la direction d'Yves

Billaud DRASSM.

2. Fouille de la rue Bernard-

du-Bois à Marseille menée

en 2005 sous la direction

d'Ingrid Sénépart, Service

archéologique de

Marseille/Inrap.

3. Fouille des Petites Bâties

à Lamotte-du-Rhône

(Vaucluse), menée en 1996 sous la direction de Didier Binder (CNRS), Luc Jallot (Afan) et Stéphanie Thiébaud (CNRS).

\section{Des vestiges ténus mais tangibles au Néolithique en Provence et en Languedoc} crue apparaît dès le Néolithique ancien, au $\mathrm{VI}^{\mathrm{e}}$ millénaire avant notre ère. Il est attesté dans le Midi de la France, où les rares habitats de plein air connus ont livré des restes d'élévations et des sols construits.

La matérialité des murs est déduite des anomalies sédimentaires repérées par la fouille en planimétrie. Cette démarche, employée au milieu des années 1990 sur le site du Baratin (Courthézon, Vaucluse), a permis la mise au jour d'un bâtiment à plan semiabsidial délimité par un cordon de fragments de molasse et de micro-galets, pouvant correspondre à une arase de mur (Sénépart, 2009). Cet établissement demeure, à l'heure actuelle, l'un des rares habitats structurés par des bâtiments associés à des sols d'occupation et à des aménagements domestiques (fosses, foyers, fours). Il doit sa notoriété à une grande structure constituée par des galets chauffés, bordée de trous de piquet. Cet empierrement a longtemps été assimilé à un dispositif de combustion. Remanié à deux occasions, il est interprété aujourd'hui comme le vestige d'un bâtiment circulaire, dont la fonction n'est pas déterminée. Le bâtiment semi-absidial, aux murs arasés, se situe à proximité immédiate de cette structure, mais leur contemporanéité n'est pas encore assurée (Sénépart, 2009) [ill. 1]. C'est également à partir de cette méthode que des arases d'une paroi interne d'un bâtiment ellipsoïdal du Néolithique impressa ont été identifiées sur le site de Peiro Signado (Portiragnes, Hérault) (Briois et Manen, 2009). Elles se présentaient sous la forme d'un linéament de petits galets de quartz. De grandes fosses, en partie sous-jacentes au bâtiment, témoignent d'une acquisition de la terre in situ.

Les sols construits restent les manifestations les plus évidentes de l'emploi de la terre. L'espace interne du bâtiment ellipsoïdal du Baratin se distingue par une succession de trois sols, de couleur blanche, fortement cimentés. Couleur et cimentation résultent ici de l'aménagement de la surface des sols par un enduit composé de fines boues calcaires, épandues à l'état humide. Le petit bâtiment néolithique cardial, de forme absidiale, reconnu sur le site de Bernard du Bois ${ }^{2}$ (colline Saint-Charles - Marseille, Bouches-du-Rhône) présente également un sol blanc et induré (Sénépart, 2008) [ill. 2]. Ce sol a été préparé à partir de limons calcaires légèrement argileux, finement mélangés et déposés à l'état pâteux. Plusieurs réfections ont été reconnues. Les vestiges de murs sont cependant fugaces, sans doute en raison des conditions taphonomiques, et rien ne permet de reconnaître les techniques constructives mises en œuvre. En revanche, les modes d'aménagement des sols témoignent d'une sélection et d'une préparation particulière des matériaux. La fonction de ces bâtiments reste encore indéterminée, bien que le caractère domestique de celui du Baratin soit attesté par les foyers qui occupent sa partie nord (Sénépart, 2009).

C'est sur le site des Petites Bâties ${ }^{3}$ (Lamottedu-Rhône, Vaucluse), que les premiers témoignages de la construction par façonnage direct ont été identifiés. Situé dans la vallée du Rhône, cet établissement du Néolithique ancien a livré de grandes excavations quadrangulaires, creusées dans une épaisse croûte carbonatée qui colmate en partie des paléochenaux tardiglaciaires (Binder et al., 2002). Dans l'une de ces structures, la base d'un pilier et un muret, édifiés par un 

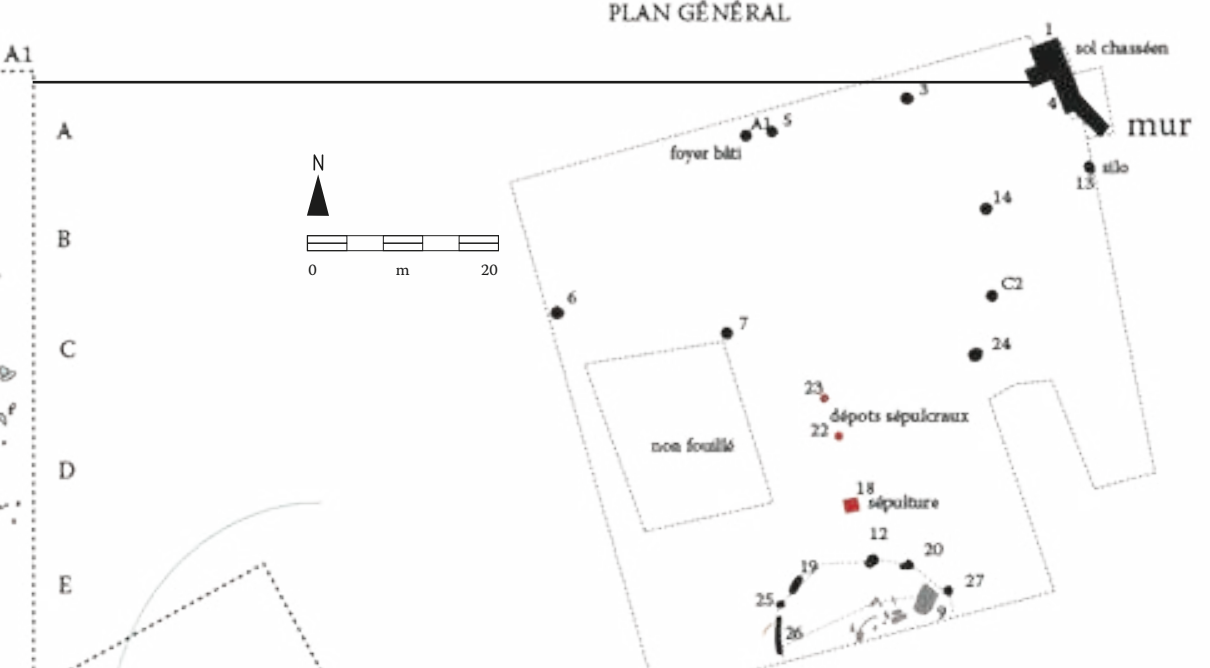

à Montpellier (Hérault)

a. Plan des fouilles et

localisation du mur en

terre crue (ST4);

b. Coupe transversale

d'une briquette façonnée

par modelage, fines rides

de compression au contact

d'un autre élément

pré-formé;

c. Vue du mur en terre crue

en cours de fouille à partir

del'ouest;

d. Mur en terre crue, plan

et coupe longitudinale.

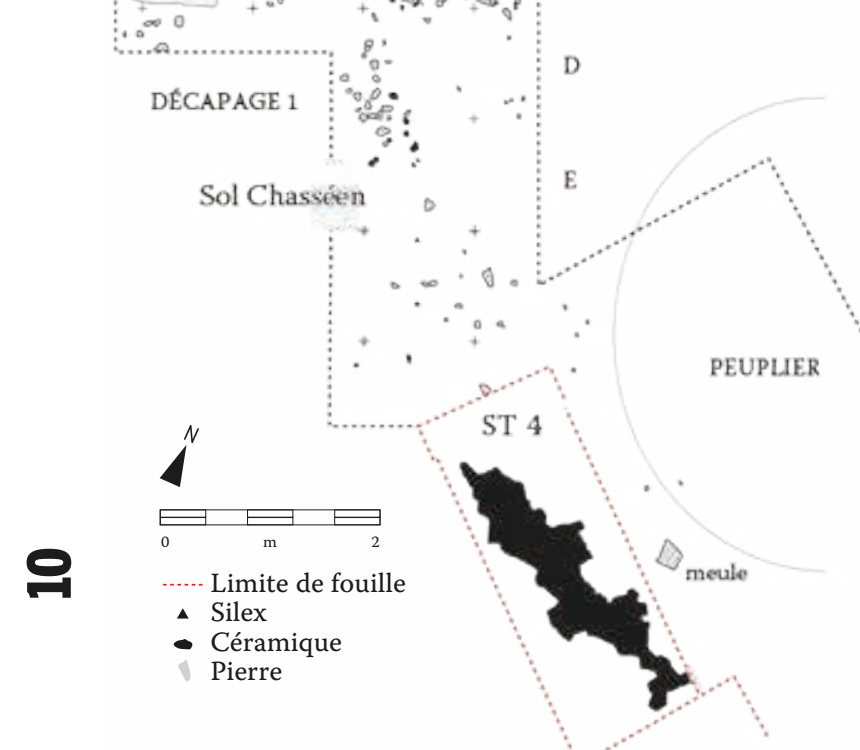

DÉCAPAGE 2
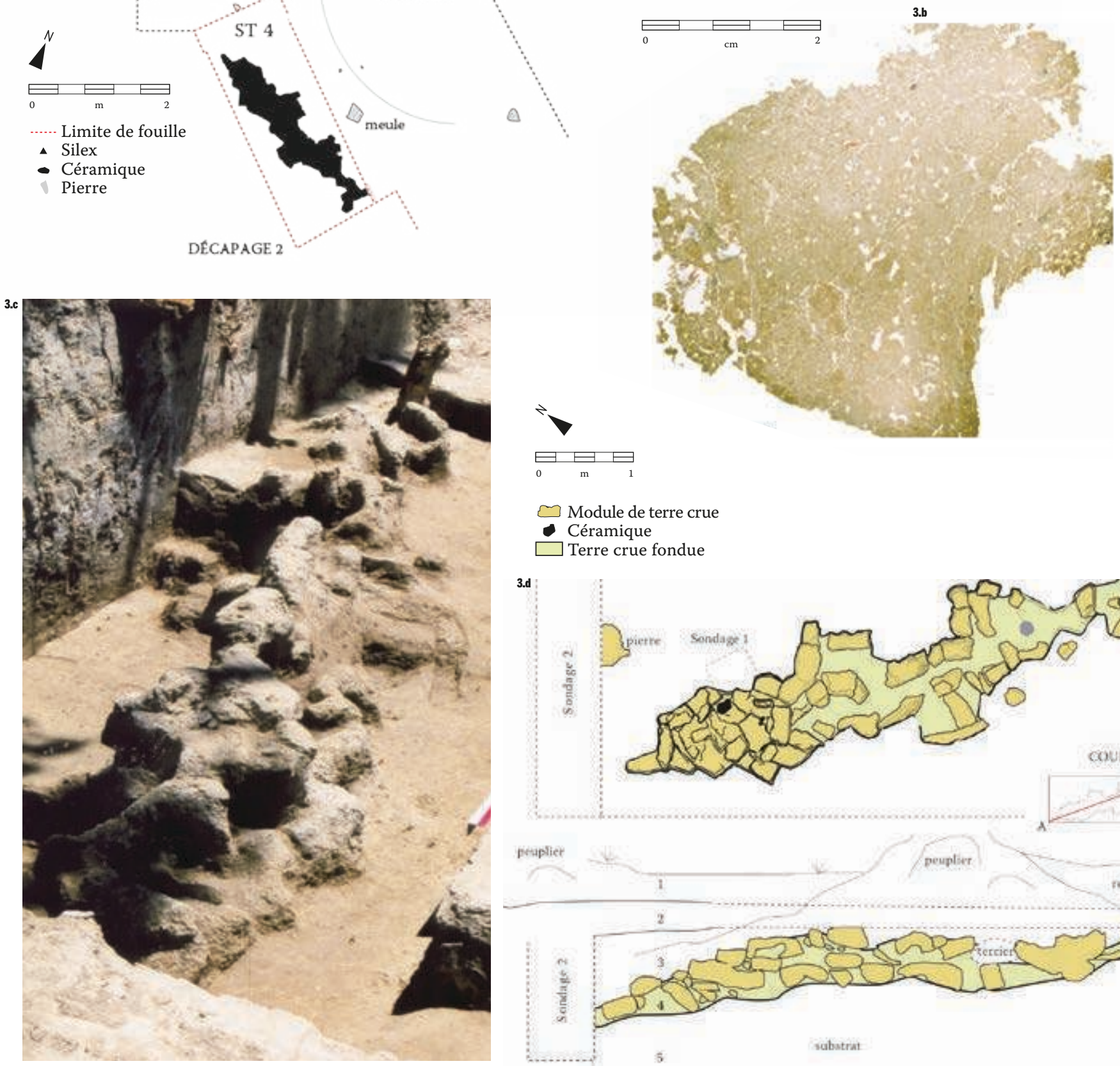

Module de terre crue

- Céramique

Terre crue fondue
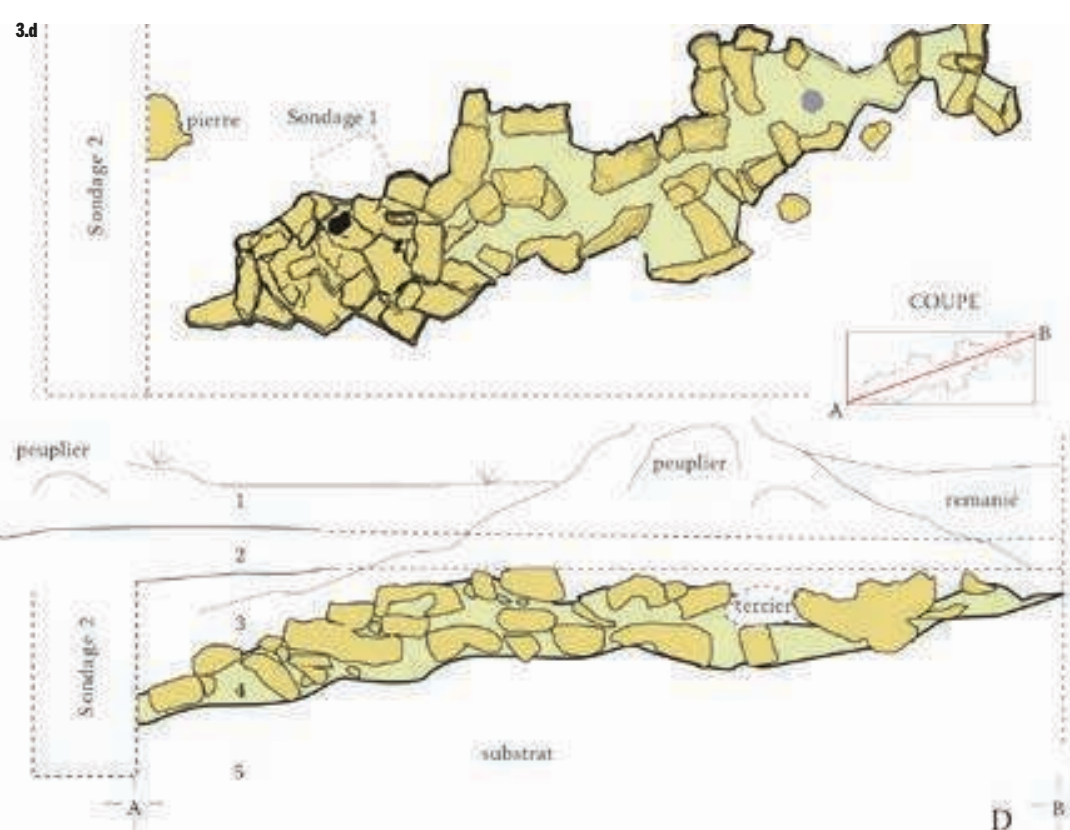
mélange de sédiments et de petits blocs de carbonates, constituent les restes d'une construction en terre crue (Jallot, 2003). La terre à bâtir était composée de limons extraits des paléochenaux, lors du creusement des excavations. La nature des aménagements n'est pas déterminée, mais dans ce cas, l'hypothèse d'un grand bâtiment a été posée. Ces vestiges témoignent d'un concept architectural différent, qui n'a pas encore trouvé d'homologue à ce jour.

\section{La construction par façonnage direct au Néolithique moyen : une mise en œuvre pour des fonctions différentes?}

C'est au Néolithique moyen que sont attestés les premiers murs en bauge. Ils sont construits par façonnage direct, au moyen d'éléments préformés, directement entassés à l'état humide (Chazelles, 2010). Ces restes architecturaux ont d'abord été identifiés dans le Midi (en Languedoc, puis en Provence) et, plus récemment, dans le centre et l'ouest de la France.

En Languedoc, l'habitat chasséen de Jacques Couur II à Montpellier ${ }^{4}$ (Hérault) est établi sur les bords du Lez. Il a livré un segment de mur, de trois mètres de long et de cinquante à soixante centimètres de large, conservé sur une hauteur de $30 \mathrm{~cm}$. Il se compose de petits éléments quadrangulaires emboîtés, similaires à des briquettes, d'une quinzaine de centimètres de long et d'environ cinq centimètres d'épaisseur. Ces éléments ont été élaborés principalement à partir de limons carbonatés issus du substrat alluvial, finement mélangés, puis pétris. La microstructure, en agrégats travaillés imbriqués, montre que la mise en forme a été réalisée par modelage, rappelant la technique du colombin. Les rides de compression développées sur les bords des éléments résultent d'un dépôt à l'état humide, compatible avec le façonnage direct [ill. 3]. La couleur des matériaux tranchait assez nettement avec la couche d'occupation de teinte plus sombre. Situé près de la limite d'emprise de la fouille, ce mur n'a pu être suivi en totalité. La forme du bâtiment qu'il composait demeure inconnue. Néanmoins, d'autres vestiges attestant de constructions en terre caractérisent cet habitat : débris comblant une structure de combustion et pains de terre fabriqués à partir de limons et de sables alluviaux empilés dans une fosse (Jallot et al., 200o).

En Provence, le site de Nédélec, à Marseille ${ }^{5}$ (Bouches-du-Rhône), est installé sur le versant de la colline Saint-Charles où il s'étage sur plusieurs replats (Sénépart, 2010). Il s'agit d'un site stratifié où une succession d'occupations, courant du Néolithique moyen final au Néolithique récent, ont été reconnues. Les vestiges architecturaux sont établis sur deux des replats de cet établissement. Il s'agit de petits tronçons de murs, de 50 à $150 \mathrm{~cm}$ de long sur 30 à $40 \mathrm{~cm}$ de large, conservés sur deux à trois assises, relevant d'un procédé constructif similaire à celui du site de Jacques Cour. Cependant, les éléments sont de morphologie différente et se présentent sous la forme de boules de terre, de taille et de forme variables [ill. 4]. Ils sont également façonnés par modelage, comme le montre leur organisation structurale. La terre à bâtir est préparée à partir d'un mélange de limons argileux et de sables issus du substrat géologique (marne), d'un horizon colluvial antérieur à l'occupation néolithique, et de sols d'occupation chasséens. Les tronçons de murs sont composés d'un entassement de ces modules, sur plusieurs assises. Ils ont été tronqués par les aménagements historiques urbains et la forme des bâtiments qu'ils composaient reste donc inconnue. Néanmoins, les sols d'occupation auxquels ils sont associés appartiennent à un espace extérieur et témoignent d'un environnement construit (Wattez et Onfray, 2014).

En Beauce, les murs reconnus sur le site de Villeneuve-sur-Conie (Loiret) sont édifiés en modules quadrangulaires limoneux, dont la teinte jaune contraste fortement avec les sédiments encaissants [cf. encadré 1, p. 20].

La forme des architectures, pour ces sites, nous échappe principalement en raison des limites d'observation. Ce n'est pas le cas du site de Lillemer (Ille-et-Vilaine), localisé dans la baie du MontSaint-Michel, où les bâtiments en bauge (briques) présentent un plan aggloméré [cf. encadré 2, p.22].

À côté de ces constructions qui reflètent peutêtre la maison ou les dépendances d'unités familiales, des vestiges, mis au jour sur le site de Château Percin à Seilh ${ }^{\mathbf{6}}$ (Haute-Garonne), attestent d'un dispositif architectural d'une autre dimension, pour une autre destination (Pons et Gandelin, 2011). Les restes brûlés d'un rempart comblent, sur une quarantaine de mètres de long, l'un des fossés d'enceinte. Il s'agit de moellons de terre brûlés, sphériques ou ovoïdes, modelés à partir de limons argileux, légèrement sableux, provenant d'un horizon supérieur de sol brun lessivé (Pons et Gandelin, 2011). Ils peuvent atteindre une trentaine de centimètres de section. Le principe constructif s'avère particulier, associant bauge massive et structure de bois, les boules de terre présentant pour certaines des empreintes de poteaux (Gandelin et al., 2011). En l'occurrence les boules de bauge pourraient n'être que le remplissage de l'ossature en bois et ne pas être porteuses.

Ces différents exemples éclairent sur les solutions adoptées, au Néolithique moyen, pour la construction en terre porteuse. Mais, si l'essentiel des informations provient du sud de la France, les vestiges identifiés en Bretagne et en Beauce montrent que l'usage de la terre crue ne relève pas de particularités locales, que ce soit en termes de conservation, de trait culturel ou encore d'environnement. Néanmoins, les données restent encore lacunaires pour cette phase du Néolithique. Peu de sites ont, à ce jour, livré des restes de construction en relation avec les sols d'occupation.
Cour II, Port Mariane, à

sous la directionée en 19

5. Fouille du site de l'avenue

Charles-Nédélec à

2007 sous la direction

d'Ingrid Sénépart

(Ville de Marseille)

Château Percin à Seih

(Haute-Garonne) menée

en 2007-2008 sous la

direction de Fabrice Pons

(Inrap). 

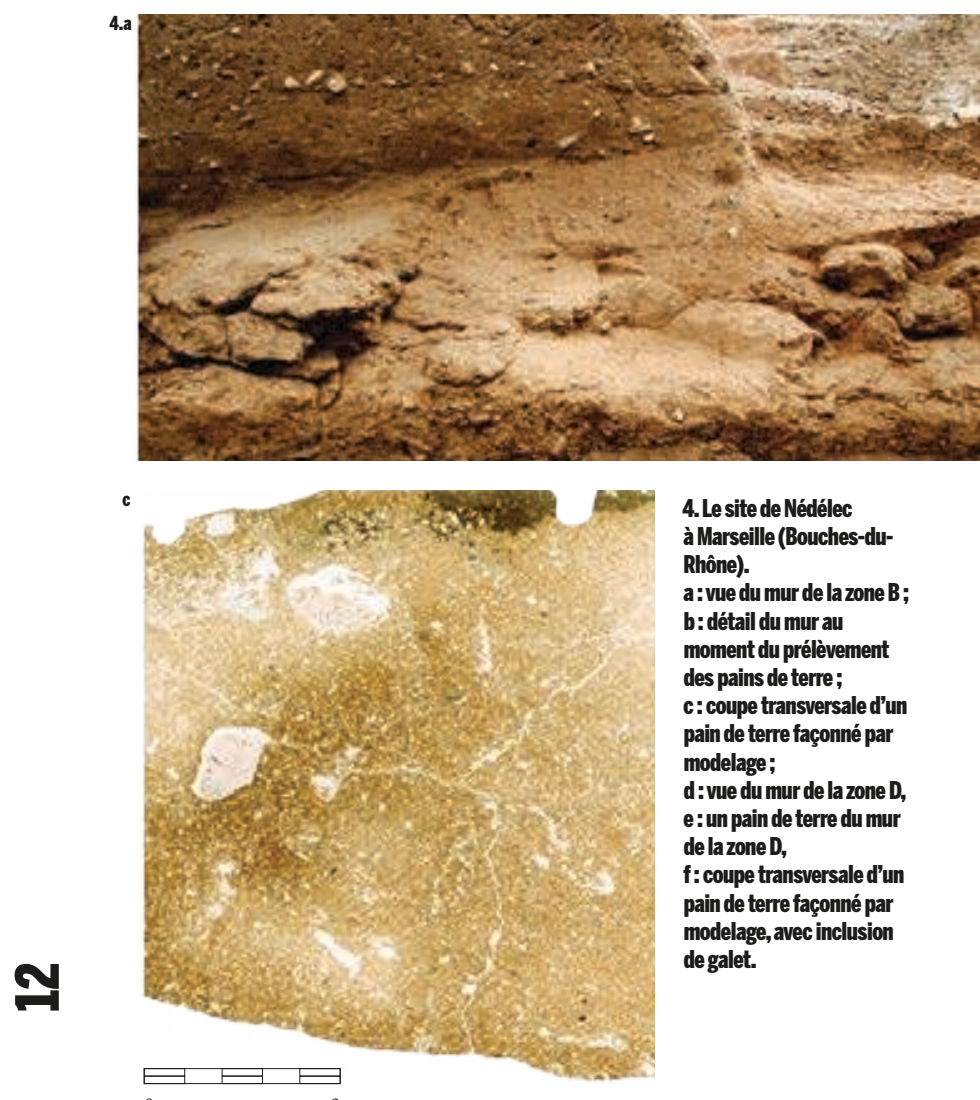

4. Le site de Nédélec

à Marseille (Bouches-du-

Rhône).

a: vue du mur de la zone $B$;

b: détail du mur au

moment du prélèvement

des pains de terre ;

c: coupe transversale d'un

pain de terre façonné par

modelage;

d: vue du mur de la zone $D$,

e : un pain de terre du mur

de la zone $D$,

$f:$ coupe transversale d'un

pain de terre façonné par

modelage, avec inclusion

de galet.

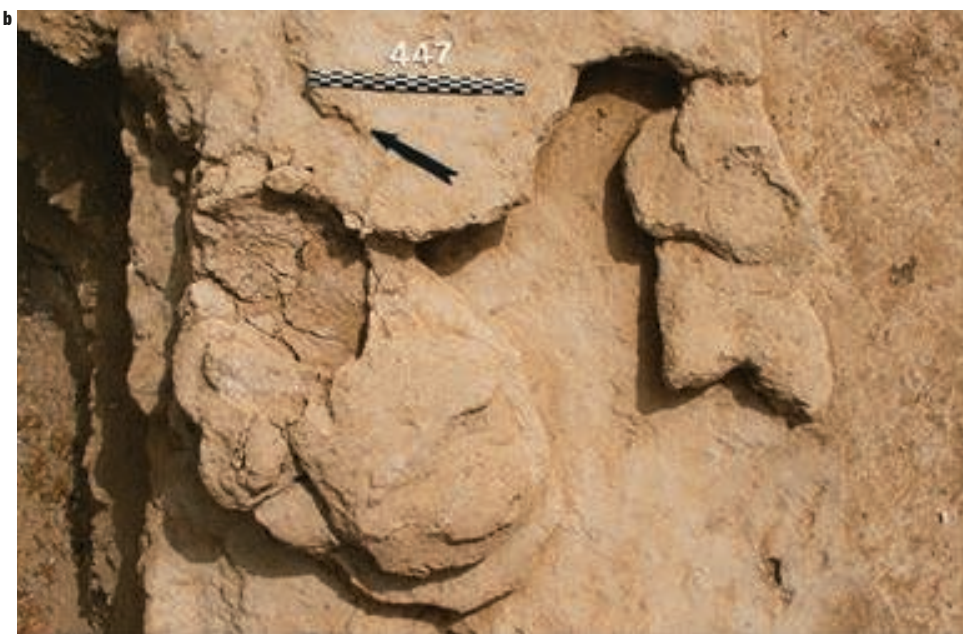

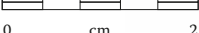
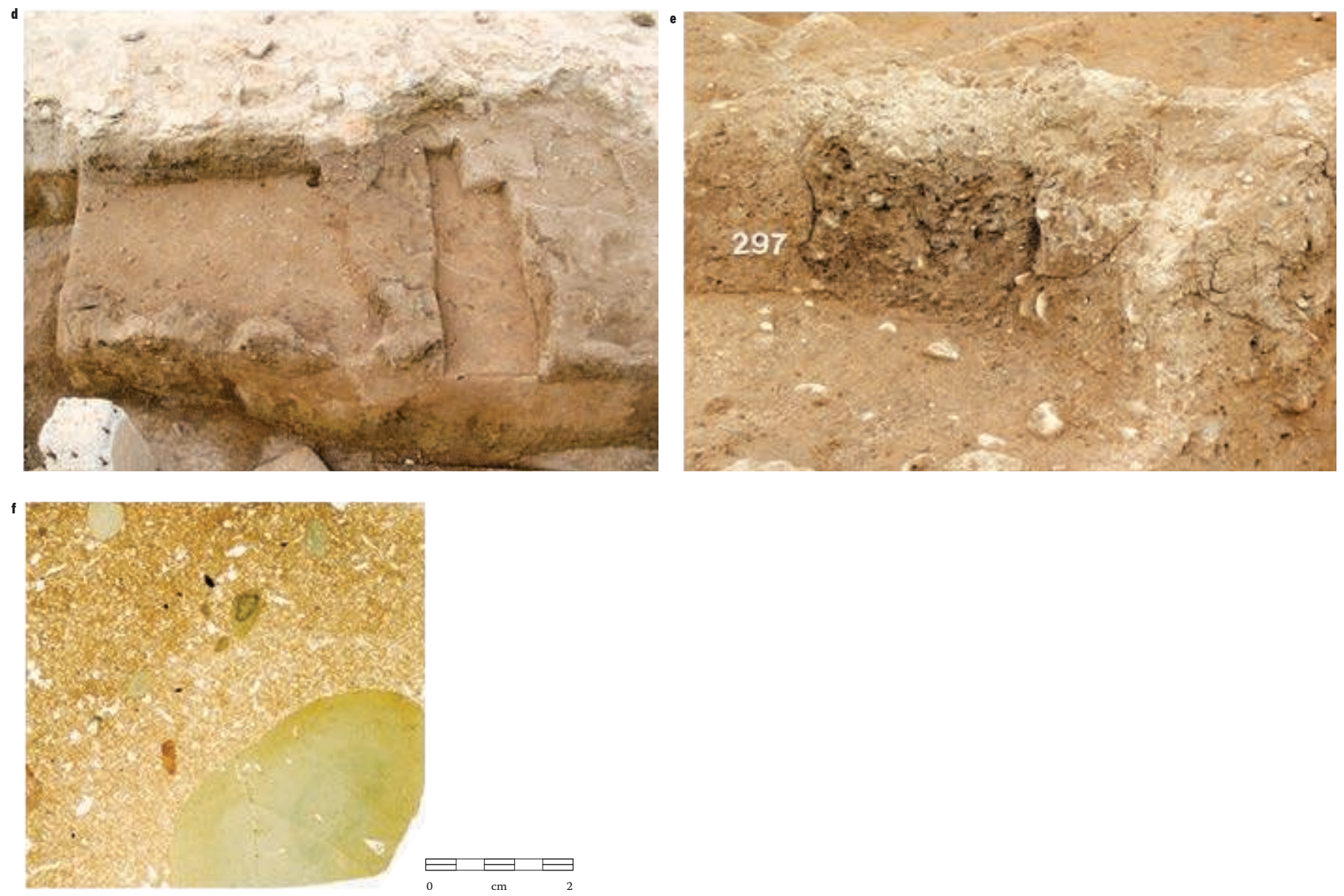
Si la base documentaire est encore faible, elle laisse cependant entrevoir une grande diversité des procédés, tant pour édifier l'habitat commun, que pour matérialiser les limites de l'espace villageois.

\section{L'extension de l'usage de la terre crue au Néolithique final}

Le nombre de structures en terre crue mises au jour, toutes régions confondues et en particulier au cours d'opérations préventives, atteste l'ampleur du phénomène à partir du Néolithique final. Les formes identifiées sont pour la plupart éloquentes, depuis les bâtiments jusqu'aux aménagements des enceintes. Elles dessinent, dans certains cas, la trame villageoise [ill. 5].

En Languedoc, c'est surtout au moment où se développent les grands habitats de plaines à réseaux de fossés de la culture de Fontbouisse que les témoignages de l'utilisation de la terre crue se multiplient. Les premiers éléments probants furent d'abord repérés sur la seule base des observations archéologiques. Entre 1992 et 1999, les fouilles préventives des établissements fontbuxiens du Stade Richter (Montpellier, Hérault) et de Peirouse-ouest (Marguerittes, Gard) livrèrent des traces, alors discutées, de matériaux en terre crue. Pour le premier, des boules de terre malaxée étaient regroupées au sommet d'une très grande fosse d'extraction. Pour le second, des briques de terre soigneusement ajustées s'alignaient sur le pourtour d'une structure de cuisson. Leurs dimensions, d'une douzaine de centimètres de long pour la moitié de large, semblaient standardisées. Le site se signalait aussi par des murs de dallettes calcaires liées à la terre ainsi que par des éléments de placage de terre interprétés comme des restes d'enduits (Jallot, 2003).

D'autres témoignages d'architecture en terre ont été révélés à l'occasion de la fouille du site du Jas del Biau ${ }^{7}$ (Millau, Aveyron). Ce site comprend un grand bâtiment allongé bâti en dalles et dallettes calcaires et un ensemble de terrasses aménagées limitées par des murs en pierres sèches (Jallot et Marsac, 1998). Sur l'une des terrasses couvertes d'un pavement de dallettes, de petites unités domestiques à vocation probablement artisanale étaient construites au moyen de briquettes de terre crue. De plus petit calibre que celles du mur de Jacques Cœur II, elles relèvent cependant du même mode de façonnage (Wattez, 2003). Les matériaux employés ont été extraits des marnes calcaires locales et des sols d'occupation. Dans le grand bâtiment, des traces de placages de terre et d'enduits fins sur les murs soulignaient de nouveau l'utilisation conjointe de la terre crue et de la pierre durant une phase précoce du Néolithique final.

Dans la plaine littorale, à Mauguio (Hérault), les fouilles de la Capoulière ${ }^{\mathbf{8}}$ ont apporté des éléments concluants sur la présence et la nature de l'architecture en terre néolithique. Les premières opérations, en 2000 et 2001, ont mis au jour différents vestiges attribués au groupe de Fontbouisse. Plusieurs bâtiment édifiés en moellons de terre crue modelés ont été identifiés (Jallot, 2003 ; Wattez, 2009) [ill. 6]. Les murs sont conservés sur une largeur de 0,20 à $0,50 \mathrm{~m}$, une longueur de 2 à $7 \mathrm{~m}$ et une hauteur comprise entre o,10 et $0,40 \mathrm{~m}$. Ils se caractérisent par un empilement de pains de terre, de forme et de modules très variés, pris dans un liant limonoargileux. La terre à bâtir a été préparée à partir de limons carbonatés de teinte jaune ou orangée, issus du substrat local, extraits lors du creusement des fossés. Les matériaux mis œuvre sont loin d'être homogènes et sont souvent mélangés à des sédiments anthropisés, à des restes de nattes ou de fumiers ou à des débris de matériaux façonnés, parfois brûlés, ces derniers témoignant du remploi d'éléments issus d'autres structures démantelées. Sur l'une des façades, un enduit épais composé de limons argileux et de restes végétaux (amas de phytolithes) a pu être identifié par l'étude micromorphologique (Wattez, 2009). Les informations, très riches, recueillies au cours des fouilles extensives menées de 2004 à 2008 ont permis d'approfondir nos connaissances sur la forme des bâtiments, leur implantation ainsi que sur les modalités de préparation et de mise en œuvre de la terre à bâtir, dans sa fonction porteuse (Gutherz et al., 2010). Elles confirment notamment le creusement des fossés pour l'installation de bâtiments encavés, une autre caractéristique de cet habitat. Ce lien entre bâtiment de plain-pied et aménagement souterrain renvoie également aux traditions architecturales des villages fontbuxiens en pierres sèches de l'arrière-pays.

Entre temps, en 2001, la fouille extensive du site du Mas de Vignoles 4 (Nîmes, Gard) confirma la présence d'aménagements en terre comme des sols construits ou des segments de mur édifiés par façonnage direct (Jallot, 2004). Ils étaient également installés dans des structures en creux. Des couches massives colmataient par endroits le remplissage de ces structures (fosses, fossés). Leur mode de formation a permis de préciser leur identité : certaines résultaient de l'érosion progressive, au fil de l'occupation, de structures de terre crue, adjacentes mais non conservées, d'autres correspondaient à des couches de démolition destinées à remblayer les fosses. La microstratigraphie des remplissages a ainsi révélé plusieurs phases d'aménagement et de réfection de l'espace. Ces couches massives, déjà définies pour les périodes récentes (Cammas, 2003), apparaissent essentielles pour aborder la structuration et l'évolution de l'habitat néolithique (Wattez, 2009). Depuis 2010, la plupart des fouilles conduites sur des sites du Néolithique Final en Languedoc oriental confirment la présence de constructions en bauge. On peut aujourd'hui citer d'autres exemples comme l'habitat de la Caunelle à Juvignac (Hérault) ${ }^{\mathbf{9}}$, celui préfontbuxien de la Cavalade à Montpellier (Hérault) ${ }^{\mathbf{1 0}}$ ou encore celui 
5. L'utilisation de la terre crue dans les habitats du

Néolithique final en

Languedoc oriental.

a. Le Jas del Biau (Millau,

Aveyron), briquette;

b. Stade Richter

(Montpellier, Hérault),

fosse de préparation de

mottes de terre;

c. Le Terruge (Collias, Gard),

bouchon de terre crue de

silo;

d. Peirouse Ouest

(Marguerittes, Gard), trace

d'enduit sur mur de pierres

sèches;

e. Capoulière 4 (Mauguio,

Hérault), base de four à

dôme en cloche ;

f. Capoulière 4 (Mauguio,

Hérault), colmatage de

briques de terre crue;

g. Capoulière 4 (Mauguio,

Hérault), épandage de

torchis (sole?).
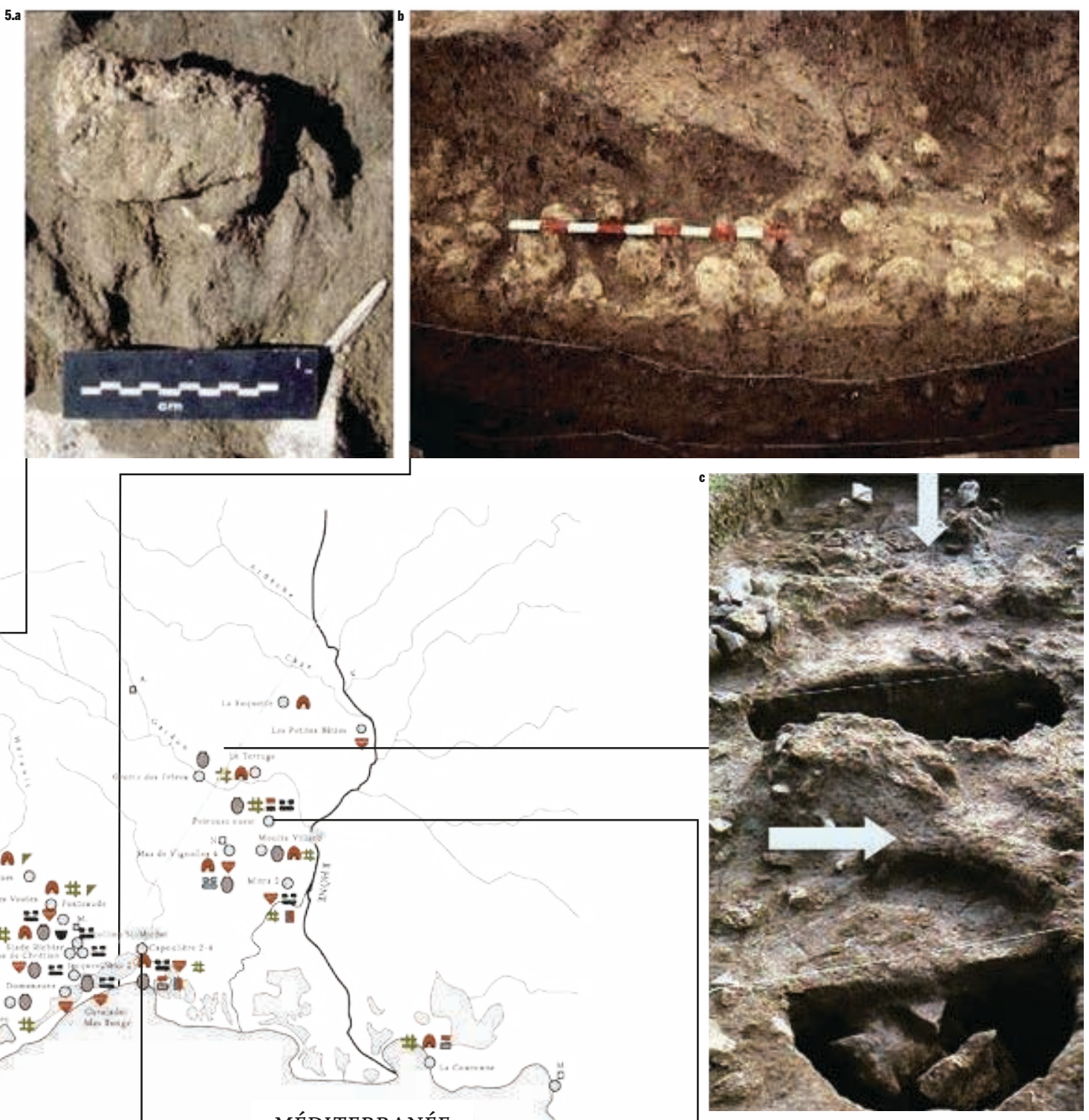

MÉDITERRANÉE

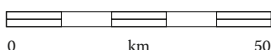

Architexture mixte (terre et pierre)

- Fosse de préparation

Vases et objets en terre crue

$\checkmark$ Couche massive

- Éléments modulaires, mur

I Enduits

\# Accumulation de torchis

$\nabla$ Toiture mixte (terre et pierre)

A Fours en terre crue ou fragments isolés
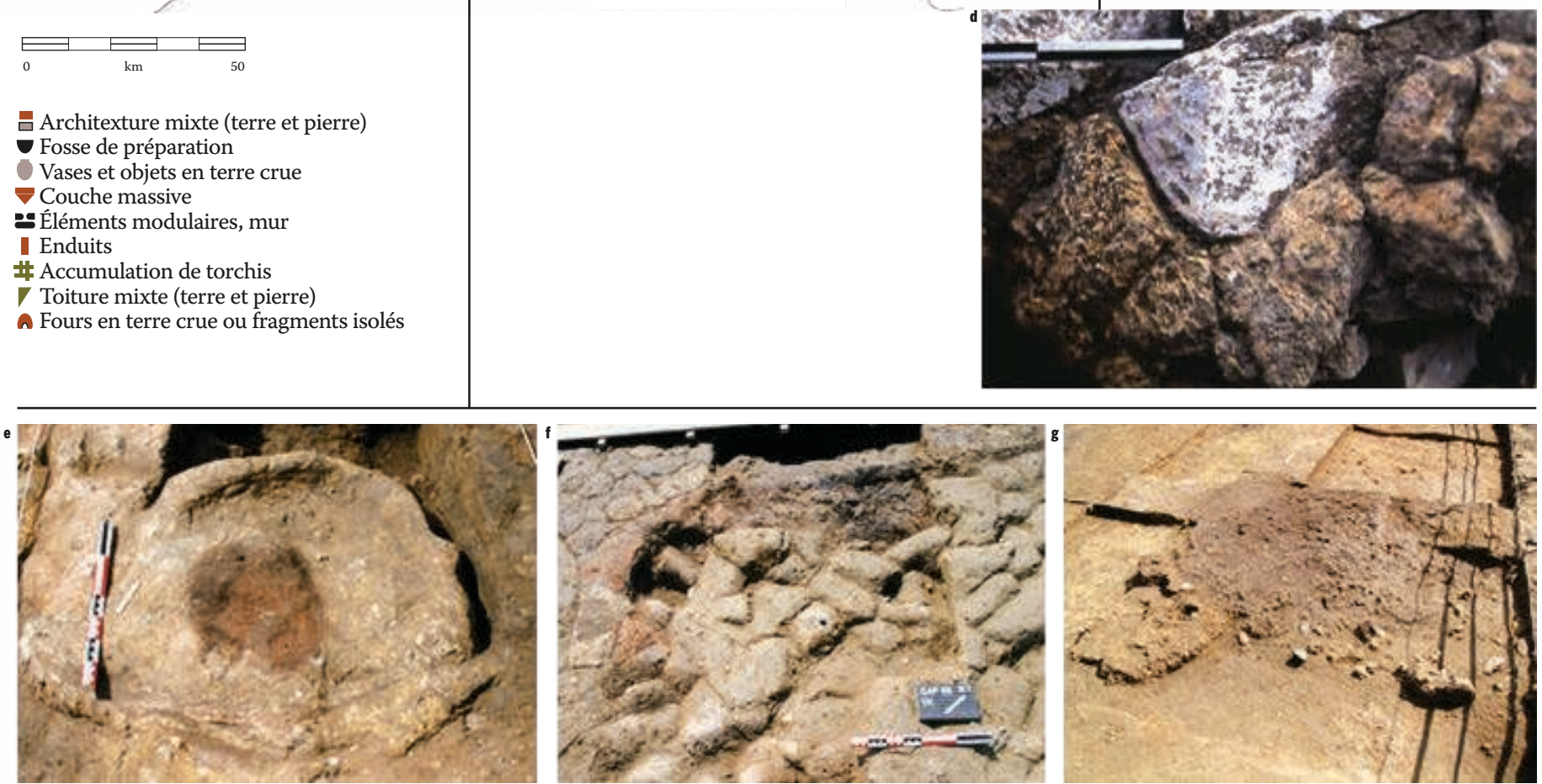
6.a

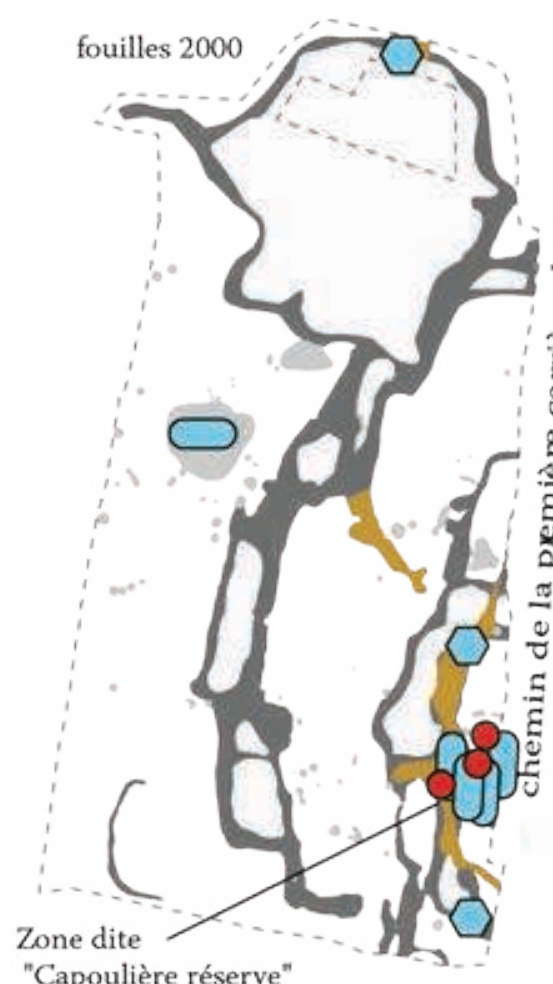

"Capoulière réserve"

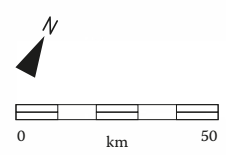

$\star$ Couches d'incendie

- Fours et foyers en surface

צ Bucrâne (dépôts intentionnels)

ir Objet en cuivre (nombre : 1 ou 2)

$\nabla$ Dépôt de faune

- Concentrations d'aménagements

$\square$ Murs en terre crue (bâtiments démantelés)

$\square$ Murs en terre crue (aménagements ponctuels) U.6 Unités de fouilles

U.A en terre crue

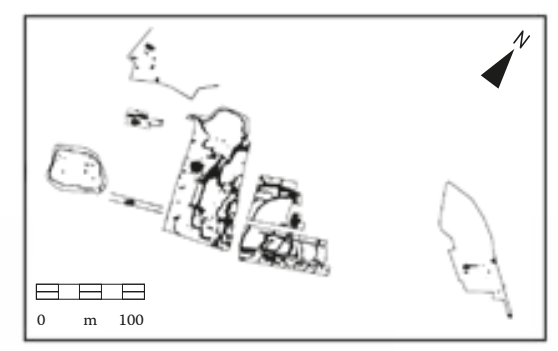

fouilles 2004-2008
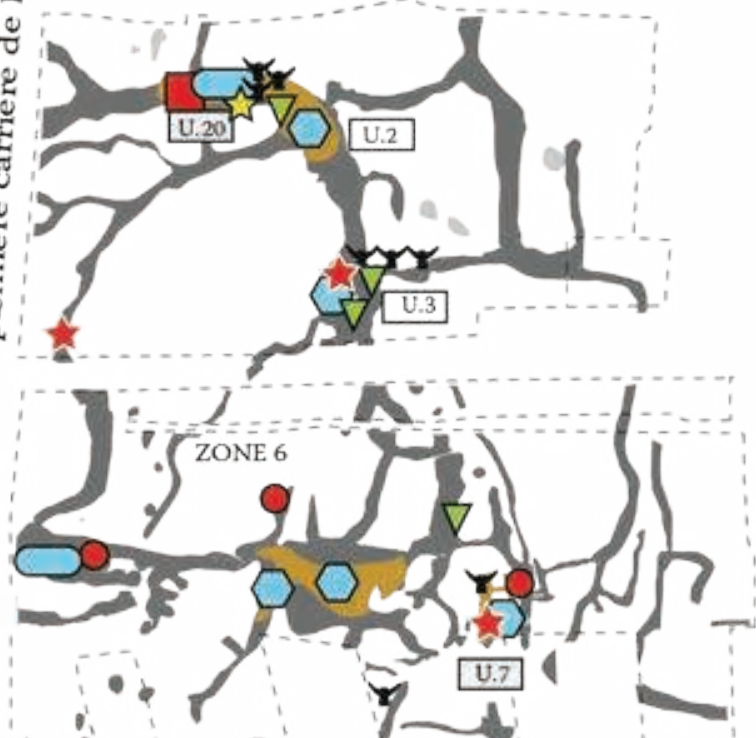

bâtiment 3

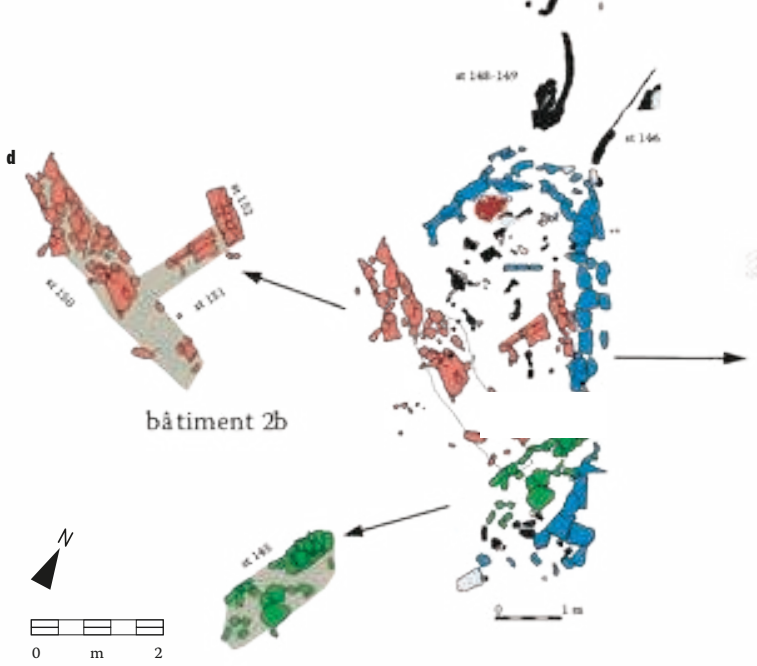

bâtiment $2 \mathrm{c}$

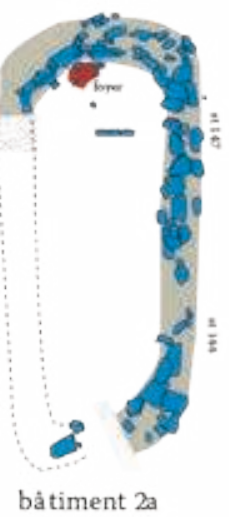

bå timent $2 \mathrm{a}$
6. La Capoulière 2 et 4

à Mauguio (Hérault).

Néolithique final (culture

de Fontbouisse).

c. Lame mince

micromorphologique : pain

de terre façonné par

imbrication de deux

a.Plan de la zone centrale mottes modelées (analyse

et emplacement des

constructions en terre

crue (fouilles L. Jallot,

2000-2008);

b. Mur en mottes de terre

crue et enduit (fouilles

C.Georjon);
J.Wattez).

d. Murs en briques de terre

et interprétation d'un

bâtiment (fouille L.Jallot).
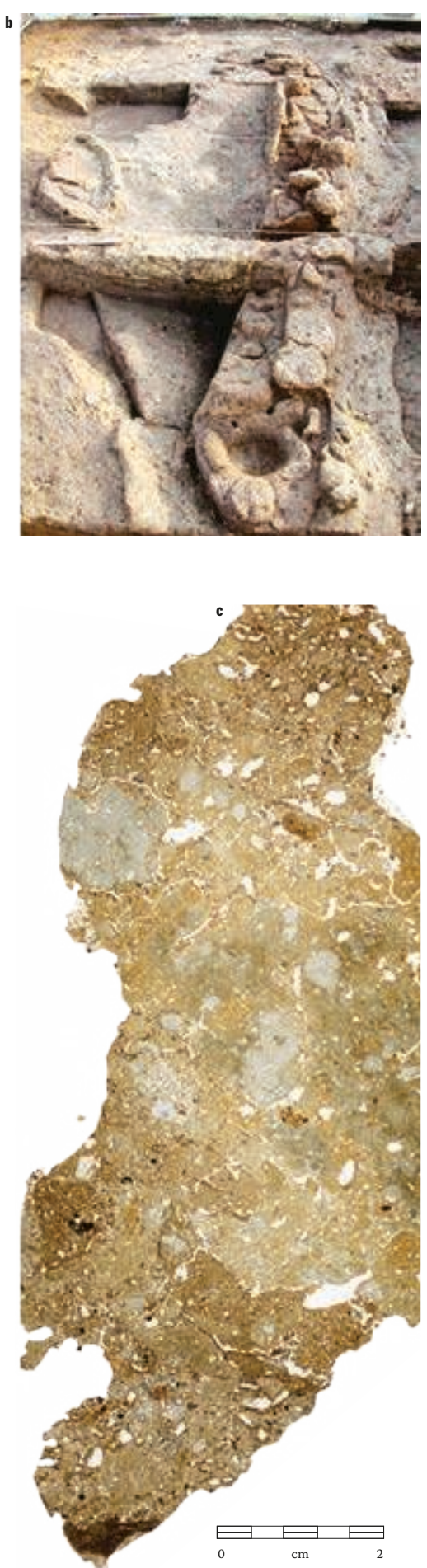


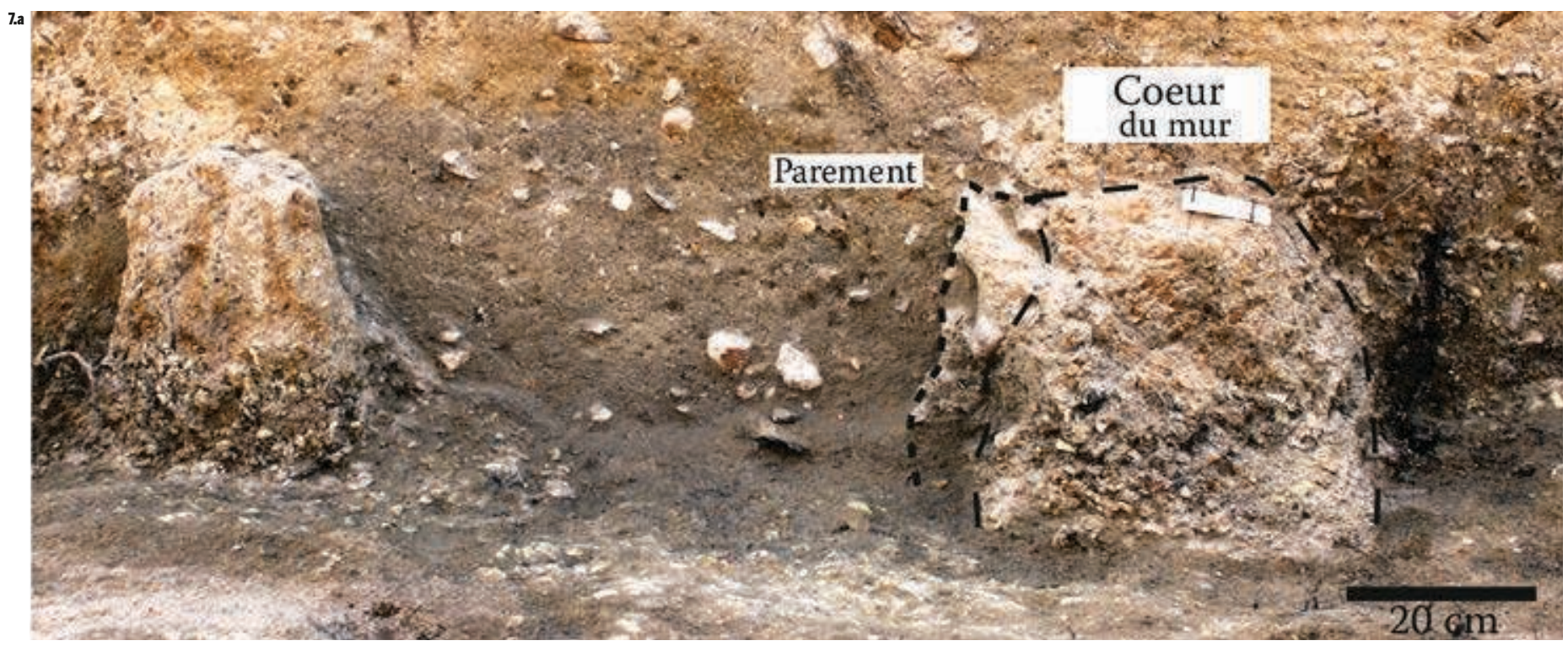

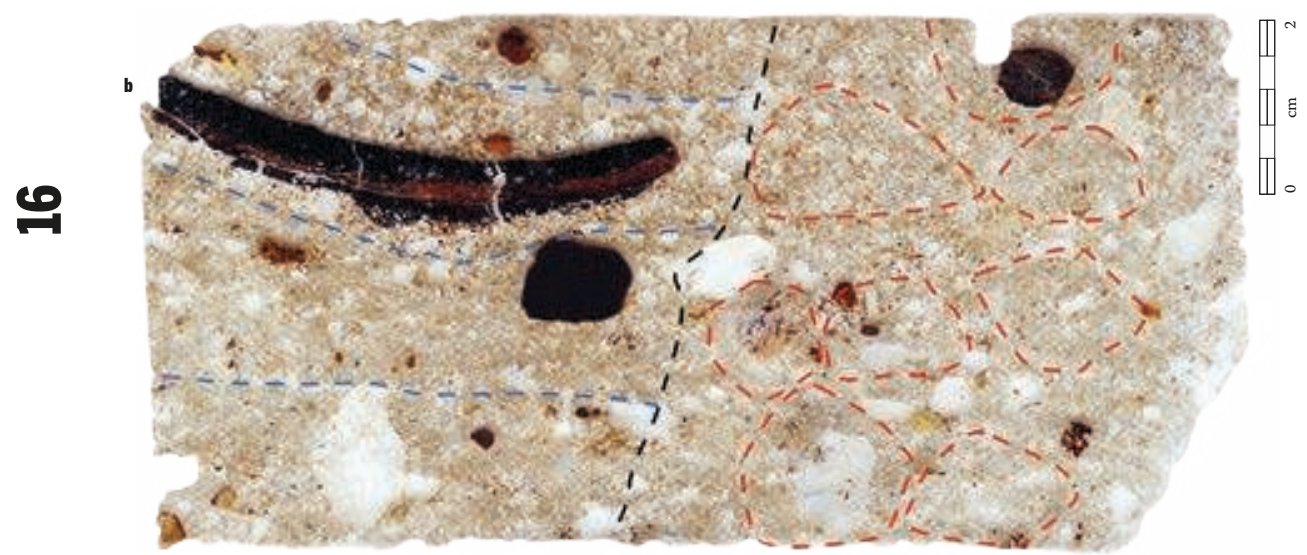

Parement du mur

Mélange homogène, finement préparé

Apport lité et fortement compacté
Partie interne du mur

Matériaux plus grossiers modérement malaxés et mis en place par apport massif
7. Le site du Bois d'Adrien à Maillé (Indre-et-Loire) a. Sondage 9, coupe de deux murs en terre crue sur celui de droite, distinction entre la partie interne du mur et le parement;

b.Scan de lame mince. À gauche, parement du mur et à droite, partie interne du mur;

c. Fouille en planimétrie d'un sol constitué de pavés (limites) (Transect 1);

d. Scan de lame mince d'un sol pavé - limite entre deux pavés posés sur un radier de terre préparé.À gauche, le pavé est constitué de concrétions ferrugineuses lui conférant une couleur rouge.
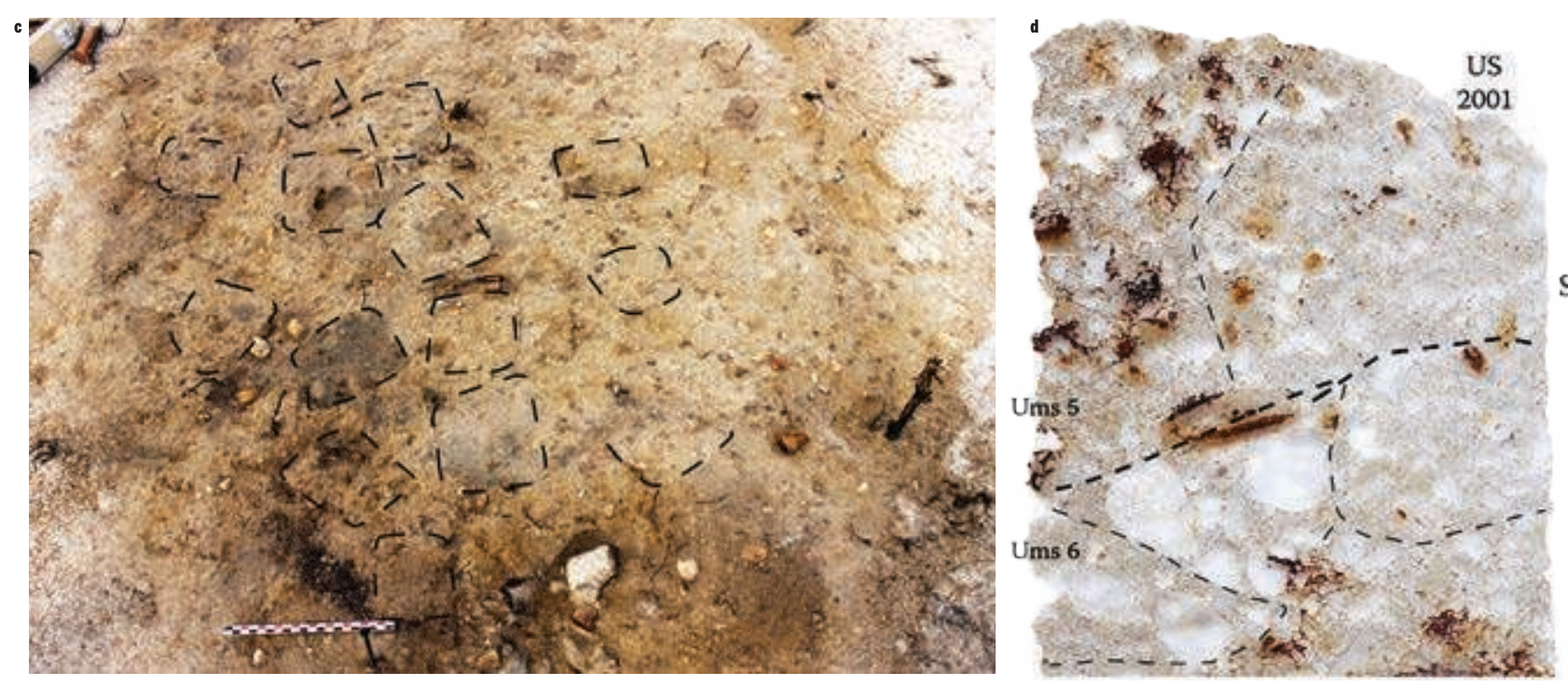

Pavés

Sol construit

Radier

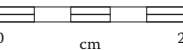


de la Colline Saint-Michel à Montpellier (Hérault) ${ }^{\mathbf{1 1}}$ (Jallot, 2014).

La documentation s'est enrichie récemment avec la découverte de dispositifs architecturaux associés aux enceintes : ceux des sites de Mitra à Nîmes $(\text { Gard })^{\mathbf{1 2}}$ ou de Pascale et Bérange à SaintBrès (Hérault) sont édifiés en boules de terre [cf encadré 3, p 24].

Les établissements de plaine du Néolithique final languedocien sont étendus. Leur configuration, particulière, est qualifiée de «fossoyée », car matérialisée par des ensembles de fosses et de fossés dans lesquels les vestiges architecturaux sont préservés. La compréhension de l'organisation villageoise pâtit de l'absence de sols d'occupation extérieurs. La situation apparaît différente dans le nord de la France, où l'architecture en terre est conservée dans des sites stratifiés. Très récemment, deux sites exceptionnels ont été découverts à l'occasion d'opérations d'archéologie préventive.

En Touraine, le site du Bois d'Adrien à Maillé (Indre-et-Loire) ${ }^{\mathbf{1 3}}$ est localisé sur une haute terrasse alluviale, en rive gauche de la vallée de la Vienne, en amont de la confluence avec la Creuse. La détection des structures de terre crue, dès le début de l'opération, a orienté la stratégie de fouille vers un décapage extensif pour délimiter l'étendue du bâti et son organisation. Un plan d'agglomération a ainsi été mis au jour sur la totalité de l'emprise explorée. Il se caractérise par plus d'une vingtaine de bâtiments. Plusieurs phases relevant d'une occupation continue ont été reconnues, en plan et en coupe. Bien que les données soient encore partielles, deux phases architecturales attestent une variation dans la forme des bâtiments, ovale dans la phase 7 et quadrangulaire dans la phase 6 [ill. 7]. Pour les autres phases, les plans ne sont pas encore connus. Les maisons mesurent quatre à cinq mètres de largeur pour une dizaine de mètres de longueur. Les murs ne sont pas fondés et sont construits selon une technique originale comme le montre l'analyse micromorphologique. Les matériaux sont préparés à partir de sédiments sablo-limoneux grossiers, issus des sols alluviaux locaux, mêlés à du mobilier céramique et lithique. Celui-ci, très présent, semble être recyclé dans la construction. Les murs (de 50 à $70 \mathrm{~cm}$ de large pour 30 à $100 \mathrm{~cm}$ de hauteur) sont façonnés avec ces matériaux, déposés par apports successifs, tandis que leurs parements, d'une épaisseur de 5 à $10 \mathrm{~cm}$, sont confectionnés à partir d'un mélange plus homogène et de texture plus fine, monté par lits successifs fortement compactés. Seuls les murs de la dernière phase comportent un radier de pierre d'origine alluviale (phase 7). Les sols des bâtiments sont construits et, dans la plupart des cas, ancrés sur un radier ou un remblai d'installation. L'étude micromorphologique montre une certaine diversité dans leurs procédés de construction. La terre à bâtir est préparée à partir de sédiments d'origine alluviale. Elle est déposée, soit sous forme de couche continue, de texture limono-sableuse, soit sous forme de pavés quadrangulaires (8 à 10 cm de côté) façonnés à l'aide de matériaux légèrement plus grossiers (sablo-limoneux), additionnés de concrétions ferrugineuses extraites de formations marécageuses pour la phase 3, entraînant des motifs différents d'une maison à l'autre [ill. 7]. Ces concrétions sont à l'origine de la couleur rouge observée au cours de la fouille. L'hypothèse d'un ajout pour teinter les sols mérite d'être posée. Ce mode d'aménagement des surfaces est quant à lui tout à fait original pour le Néolithique. Les différentes phases de construction sont stratigraphiquement délimitées par des couches massives, décimétriques, composées d'un entassement dense de débris de matériaux de construction en terre. Ces faciès sédimentaires intermédiaires, interprétés comme des remblais, correspondraient aux phases de démolition préalables à l'implantation de nouveaux bâtiments. Entre les bâtiments, la stratification, constituée d'une séquence de sols développés sur des remblais, matérialise des voies de passage [ill. 7]. L'exemple du site du Bois d'Adrien élargit la perspective sur les façons de construire en terre des murs et des sols. Là encore, l'emploi de sédiments issus du contexte alluvial sur lequel est implanté l'habitat peut introduire un biais dans la détection de constructions en terre. Cependant, les anomalies résultant de la mise en œuvre de la terre à bâtir constituent des pistes.

Le second exemple est celui de la Fosse Blanche (Prasville, Eure-et-Loir). Les diagnostics réalisés sur plus de 5 ha ont mis en évidence plusieurs ensembles de bâtiments édifiés en bauge [cf. encadré 4, p. 26].

La construction en terre n'est cependant pas une découverte récente dans le nord de la France. Ainsi, en Mayenne, les vestiges d'un mur de terre conservé sur près de $5 \mathrm{~m}$ et préservé sur 25 à $30 \mathrm{~cm}$ de hauteur sont signalés sur le site du Plantis à Oisseau en 1985-1986 (Letterlé, 1986). À l'époque, il n'a pas été observé de traces d'armatures en bois et la nature des éléments de construction (terre massive tassée ou éléments modulaires de terre) n'est pas précisée.

L'habitat en terre crue peut laisser des traces plus fugaces. En plateau de Beauce, sur le site stratifié des Friches de Flotville (Sours, Eure-etLoir), la répartition du matériel au sol a mis en évidence trois plans d'habitation du Néolithique récent, de tradition Horgen (Hamon et al., 2014). Ces bâtiments ne sont pas signalés par des éléments porteurs de type poteaux mais par des anomalies sédimentaires. Celles-ci dessinent des fantômes de murs qui délimitent des plans cohérents et répétitifs. Il pourrait s'agir de sablières de bois disposées dans des tranchées peu profondes. Le sol est en partie conservé. Deux niveaux de construction sont possibles. L'étude micromorphologique des sols d'occupation et des
. Diagnostic mené Luc Jallot, Inrap.

12. Fouilles menées en Sendra.

13. Fouilles menées en 2013 sous la direction de Tony Hamon, Inrap. 
anomalies sédimentaires confirme les observations de terrain : l'usage de la terre dans la construction est identifiée de manière indirecte, soit en position d'effondrement, soit dans des zones de rejets comportant d'abondants débris de matériaux façonnés. Ces résultats restent préliminaires, l'étude étant en cours. Le site des Grands Noyers (Gas, Eure-et-Loir) ${ }^{\mathbf{1 4}}$ a livré un bâtiment seulement matérialisé par des trous de poteaux et par des concentrations de mobilier, mais qui s'est révélé être au moins en partie édifié en terre crue. En effet, l'étude micromorphologique menée sur les zones de mobiliers a permis d'identifier la base d'une élévation en bauge et des sols aménagés en terre massive (Noël et Onfray, sous presse). La terre à bâtir provenait essentiellement de la partie supérieure d'un sol brun lessivé dont les caractères sont similaires à ceux des couches d'occupation.

Nombre de questions sur la construction en terre néolithique en milieu tempéré restent encore en suspens. Néanmoins, quelques éléments de réponses et pistes de réflexion peuvent être proposées.

Premièrement, la construction en bauge est avérée sur l'ensemble du territoire dès le Néolithique ancien. Les indices recueillis témoignent de la généralisation de cette technique pendant tout le Néolithique. Il est donc certain que l'emploi du matériau terre, encore peu ou mal détecté, constitue une grande partie des architectures néolithiques.

Deuxièmement, la terre peut être associée à d'autres matériaux comme le bois ou la pierre. Qu'elle soit utilisée seule ou non, son emploi peut relever de différentes contraintes : culturelles, techniques, esthétiques, etc., qu'il est encore difficile de percevoir mais que l'on doit garder à l'esprit... Par exemple, les constructions en terre peuvent aussi reproduire des schémas d'organisation spatiale et des mises en œuvre obtenus ailleurs à partir d'autres techniques (cf. supra, site de la Capoulière).

Troisièmement, l'usage de la terre crue ne semble pas lié à des fonctions spécifiques du bâti. Elle est utilisée dans les petits édifices (habitations, greniers) et dans les architectures monumentales (enceintes), relevant plutôt de l'espace collectif comme dans le cas de Château-Perçin. Ce constat appelle un certain nombre de questions touchant à l'origine des pratiques constructives en terre, à la transmission des savoirs et au caractère vernaculaire des architectures néolithiques.

Enfin, les vestiges en terre crue sont préservés dans des contextes topographiques, géomorphologiques et pédologiques variés. Les conditions climatiques locales postérieures aux occupations n'ont pas joué un rôle significatif sur leur conservation. L'artificialisation des sols, au cours des périodes historiques et contemporaines, est davantage en cause. La construction en terre a laissé des traces encore discernables dans le paysage, comme le montre la topographie des champs cultivés de la Fosse Blanche à Prasville ou de Villeneuve-sur-Conie [encadrés 1 et 4]. Ainsi, la mise au jour de bâtiments dont les plans sont partiellement dégagés, mais aussi de segments de murs qui peuvent être des limites d'autres espaces, apporte un nouvel éclairage sur la trame villageoise et sur l'organisation des habitats au sein de leur territoire durant le Néolithique. 


\section{Références bibliographiques}

BILLAUD Y., 2005, « Traces fugaces et architecture de terre au Bronze final : le cas de Laprade (Lamotte-duRhône, Vaucluse, TGV Méditerranée) », in Buschenschutz O. et Mordant C. (DiR.), Architectures protohistoriques en Europe occidentale du Néolithique final à l'âge du Fer, Actes du $127^{\circ}$ Congrès national des sociétés historiques et scientifiques, (Nancy, 2002), Paris, édition du CTHS, p. 389-404.

Binder D., Jallot L., ThiéBault S., 2002, « Fiche nº 9: les occupations néolithiques des Petites Bâties, (Lamothe-du-Rhône, Vaucluse) », in Archéologie du TGV-Méditerranée Préhistoire, Fiches de synthèse, Tome 1, la Préhistoire, Lattes, ADAL, Monographies d'Archéologie Méditerranéenne, 8, p. 103-122.

BRIOIS F., MANEN C., 2009, «L'habitat néolithique ancien de Peiro Signado à Portiragnes (Hérault) », in BeECHING A. et Sénépart I. (DIR.), De la maison au village : l'habitat néolithique dans le Sud de la France et le Nord-Ouest méditerranéen, Actes de la table ronde des 23 et 24 mai 2003 (Marseille, Musée d'histoire de la ville de Marseille), Mémoire de la SPF $\mathrm{n}^{\circ} 48$ Paris, Société Préhistorique Française, p. 31-38.

BROCHIER J.-L., 1994, «Étude de la sédimentation anthropique, la stratégie des ethnofaciès sédimentaires en milieu de constructions en terre », Bulletin de correspondance hellénique, 118-2, p. 619-645.

CAMmAS C., 2003, « L'architecture en terre crue à lâge du Fer et à l'époque romaine : apports de la discrimination micromorphologique des modes de mise en œuvre», in Chazelles C.-A. DE, Klein A. (DIR.), 2003, Échanges transdisciplinaires sur les constructions en terre crue, vol. 1, Terre modelée, découpée ou coffrée, matériaux et modes de mise en oeuvre, Actes de la table-ronde de Montpellier (17-18 novembre 2001), Montpellier, éditions de l'Espérou, p. 33-53.

Chazelles C.-A. de, 2005, « Les architectures en terre crue du Sud de la France aux âges des métaux (Bronze final-âge du Fer) », in Buschenschutz O. et Mordant C. (DIR.)., Architectures protohistoriques en Europe occidentale du Néolithique final à l'âge du Fer, Actes du $127^{\circ}$ Congrès national des sociétés historiques et scientifiques (Nancy, 2002), Paris éditions du CTHS, p. 25-39.

Chazelles C.-A. de, 2007, « La bauge dans les constructions du Languedoc et du Roussillon d'après les témoignages archéologiques du Néolithique à la fin du Moyen-Age. Essai de synthèse », in Patte E. ET STREIFF F. (DIR.) L'architecture en bauge en Europe, Actes du colloque d'Isigny-sur-Mer (12-14 octobre 2006), Les Veys, Parc naturel régional des marais du Cotentin et du Bessin, p. 211-234.

Chazelles C.-A. de, 2010, « Terre modelée et terre moulée, deux conceptions différentes de la construction en terre », in CARvais R., GuILlerme A., Nègre V., Sakarovitch J. (DIR.), Edifice et artifice. Histoires constructives, recueil de textes issus du Premier congrès francophone d'Histoire de la construction (Paris, juin 2008), Paris, Picard, p. 411-420.

Chazelles C.-A. De et Poupet P., 1985, « La fouille des structures de terre crue : définitions et difficultés », Aquitania, 3, p. 149-160.
Gandelin M., Pons F, Chazelles C.-A. de, 2011, « L'enceinte chasséenne de Château-Perçin. Un témoignage exceptionnel d'architecture monumentale néolithique en Haute-Garonne », Archéopages, $\mathrm{n}^{\circ}$ 33, p. 12-15.

Goldberg P., Macphail R. I., 2006, Practical and theoretical geoarchaeology, Oxford, Blackwell Publishing, $456 \mathrm{p}$.

Gutherz X., Jallot L., Wattez J., Borgnon C., Roux J.-C., Thouvenot Y., Orgeval M., 2010, « L'habitat néolithique final de la Capoulière IV (Mauguio, Hérault) : présentation des principaux résultats 2004-2007 ", in SÉNépart I., Perrin T., Thirault É., BONNARDIN S. (DIR.), Marges, frontières et transgressions, Actualité de la recherche, Actes des $\mathrm{VIII}^{\mathrm{es}}$ rencontres méridionales de Préhistoire récente (Marseille, 7 et 8 novembre 2008), Toulouse, Éditions Archives d'Écologie Préhistorique, p. 413-437.

Hamon T., Creusillet M.-F., Onfray M., 2014, « Sours "Les Hauts de Flotville" (Eure-et-Loir), mise en évidence de sols néolithiques et protohistoriques en plaine de Beauce, approche et limite de terrain et d'étude », in Sénépart I., Billard C., Bostyn F., Praud I., Thirault É. (DIR.), Méthodologie des recherches de terrain sur la Préhistoire récente en France, Nouveaux acquis, nouveaux outils, 1987-2012, Actes des premières rencontres de Préhistoire récente Nord-Sud (Marseille, 23-25 mai 2012), Toulouse, Éditions Archives d'Écologie Préhistorique, p. 349-354.

JALLOT L., 2003, «Exemples de constructions architecturées en terre crue dans les habitats du Néolithique méridional ", in CHAZELLES C.-A. DE, KLEIN A. (DIR.), Échanges transdisciplinaires sur les constructions en terre crue, Montpellier, Éditions de l'Espérou, p. 170-183.

JALlot L (DIR.), 2004, Le Mas de Vignoles IV à Nîmes (Gard), DFS, Afan, SRA Languedoc-Roussillon, 2 vol., 13 fascicules, $1360 \mathrm{p}$.

JALLOT L., 2014, «Le site de la colline Saint-Miche (Montpellier, Languedoc) : la question de la transition Néolithique final 2-3 ", in SÉNÉPART I., LÉAndri F., Cauliez J., Perrin T., Thirault É. (DIR.), Chronologie de la Préhistoire récente dans le Sud de la France. Actualité de la recherche, Actes des $10^{\mathrm{es}}$ rencontres méridionales de Préhistoire récente (18-22 octobre 2012, Porticcio, Corse), Toulouse, Archives d'écologie Préhistorique, p. 87-135.

Jallot L., Georjon C., Wattez J., Blaizot F., Cordier L., LÉA V., BeUgnier V., 200o, «Principaux résultats de létude du site chasséen de Jacques Coeur II (Port Marianne, Montpellier, Hérault) ", in LEDUC M. VALDEYRon N. ET VAQUeR J (DIR.), Sociétés et espaces, III rencontres méridionales de Préhistoire récente (Toulouse, 6-7 novembre 1998), Toulouse, Éditions Archives d'Écologie Préhistorique, p. 281-304

JALLOT L., MARSAC P., 1998, « Travaux et recherches archéologiques de terrain, Aveyron, Millau, Jas del Biau », Bilan scientifique 1998, Direction régionale des Affaires Culturelles de Midi-Pyrénées, Service Régional de l'Archéologie de la région de MidiPyrénées, p. 67-69.

Leroi-Gourhan A., BrÉZillon M., 1972, Fouilles de Pincevent, essai d'analyse ethnographique d'un habitat magdalénien, VII esupplément à Gallia Préhistoire, Paris, CNRS, $335 \mathrm{P}$

LETTERLÉ F., 1986, «Un habitat de la fin du Néolithique le site du Plantis à Oisseau », in LetTerlé F. (DIR.) Premiers agriculteurs de la Mayenne: recherches récentes sur le Néolithique 1978-1986, Nantes, Association d'études préhistoriques et historiques des Pays de la Loire, p. 43-41.
Nö̈L J.-Y., Onfray M., sous presse, « Approche interdisciplinaire des nappes de mobilier en contexte de plateau : Le site de Gas "les Grands Noyers" (Eure-et-Loir) au Néolithique récent-final », in VANMOERKERKE J. (DIR.), Occupations et exploitations néolithiques : et si lon parlait des plateaux ? $31^{\mathrm{e}}$ colloque INTERNEO, 18-19 octobre 2013, Châlons-en-Champagne, bull. de la Société Archéologique Champenoise, t. 107, n 4, p.7-34..

Pons F., Gandelin M. (DIR.), 2011, Seihl, Château Percin (Haute-Garonne), Station d'épuration de l'Aumonnelle, Rapport d'opération, Inrap-SRA Midy-Pyrénées, Juin 2011, 613 p.

Roux J.-C., CAmmas C., 2010, « Les techniques constructives en bauge dans l'architecture protohistorique de Lattara, Lattes, Hérault (milieu $\mathrm{V}^{\mathrm{e}}$-milieu IV ${ }^{\mathrm{e}}$ s. av. n. è.) », in JANIN T. (DIR.), Premières données sur le cinquième siècle avant notre ère dans la ville de Lattara, Lattara, 21, Association pour le Développement de l'Archéologie en Languedoc, p. 219-288.

SÉNÉPART I., 2000, « Gestion de l'espace au Néolithique ancien dans le Midi de la France : l'exemple du Baratin à Courthézon (Vaucluse) », in LEDUC M. VALdeyron N. et VAQUer J (DIR.), Sociétés et espaces, $\mathrm{III}^{\mathrm{e}}$ rencontres méridionales de Préhistoire récente (Toulouse, 6-7 novembre 1998), Toulouse, Éditions Archives d'Écologie Préhistorique, p. 44-51.

SÉNÉPART I. (DIR.), 2008, « La Préhistoire récente », in SÉNÉPART I. (DIR.), 53-63, rue Bernard-du-Bois à Marseille (Bouches-du-Rhône), Rapport d'opération Inrap-SRA Provence-Alpes-Côte d'Azur, $192 \mathrm{p}$.

SÉNÉPART I., 2009, « L'habitat néolithique ancien cardial du Baratin à Courthézon (Vaucluse) », in BEECHING A. et SÉNÉPART I. (DIR.), De la maison au village: l'habitat néolithique dans le Sud de la France et le Nord-Ouest méditerranéen, Actes de la table ronde des 23 et 24 mai 2003 (Marseille, Musée d'histoire de la ville de Marseille), Mémoire de la SPF n ${ }^{\circ} 48$, Paris, Société Préhistorique Française, p. 61-72.

SÉNÉPART I. (DIR.), 2010, Boulevard Nédélec, Marseille (Bouches-du-Rhône), Rapport d'opération, InrapSRA Provence-Alpes-Côte d'Azur, $332 \mathrm{p}$

Stordeur D., WATTEZ J., 1998, «À la recherche de nouvelles clés, Étude géoarchéologique à Qdeir I, PPNB final, désert syrien ", Contributions réunies par Jacques Cauvin, Cahiers de l'Euphrate 8, p. 115-138.

WATTEZ J., 2003, « Caractérisation micromorphologique des matériaux façonnés en terre cuite dans les habitats du Sud de la France : l'exemple des sites Jacques Cour (Montpellier, Hérault), du Jas del Biau (Millau, Aveyron) et de la Capoulière (Mauguio, Hérault) », in Chazelles C.-A. DE, Klein A. (DIR.), Échanges transdisciplinaires sur les constructions en terre crue, Montpellier, Éditions de l'Eśpérou, p. 21-31.

WATTEZ J., 2009, « Enregistrement sédimentaire de l'usage de la terre crue dans les établissements néolithiques du sud de la France : le cas des sites du Néolithique Final de La Capoulière 2 et du Mas de Vignoles IV », in BeECHING A. et SÉNÉPART I. (DIR.), De la maison au village: l'habitat néolithique dans le Sud de la France et le Nord-Ouest méditerranéen, Actes de la table ronde des 23 et 24 mai 2003 (Marseille, Musée d'histoire de la ville de Marseille), Mémoire de la SPF n 48, Paris, Société Préhistorique Française, p. 199-218.

WATTEZ J., ONFRAY M., 2014, « La question des sols d'occupation néolithiques : apports de la géoarchéologie à leur identification et à leur interprétation », in SÉNÉPART I., BILlaRd C. Bostyn F., Praud I., Thirault É. (Dir.), Méthodologie des recherches de terrain sur la Préhistoire récente en France, Nouveaux acquis, nouveaux outils, 1987-2012, Actes des premières rencontres de Préhistoire récente Nord-Sud (Marseille, 23-25 mai 2012), Toulouse, Éditions Archives d'Écologie Préhistorique, p. 317-348. 


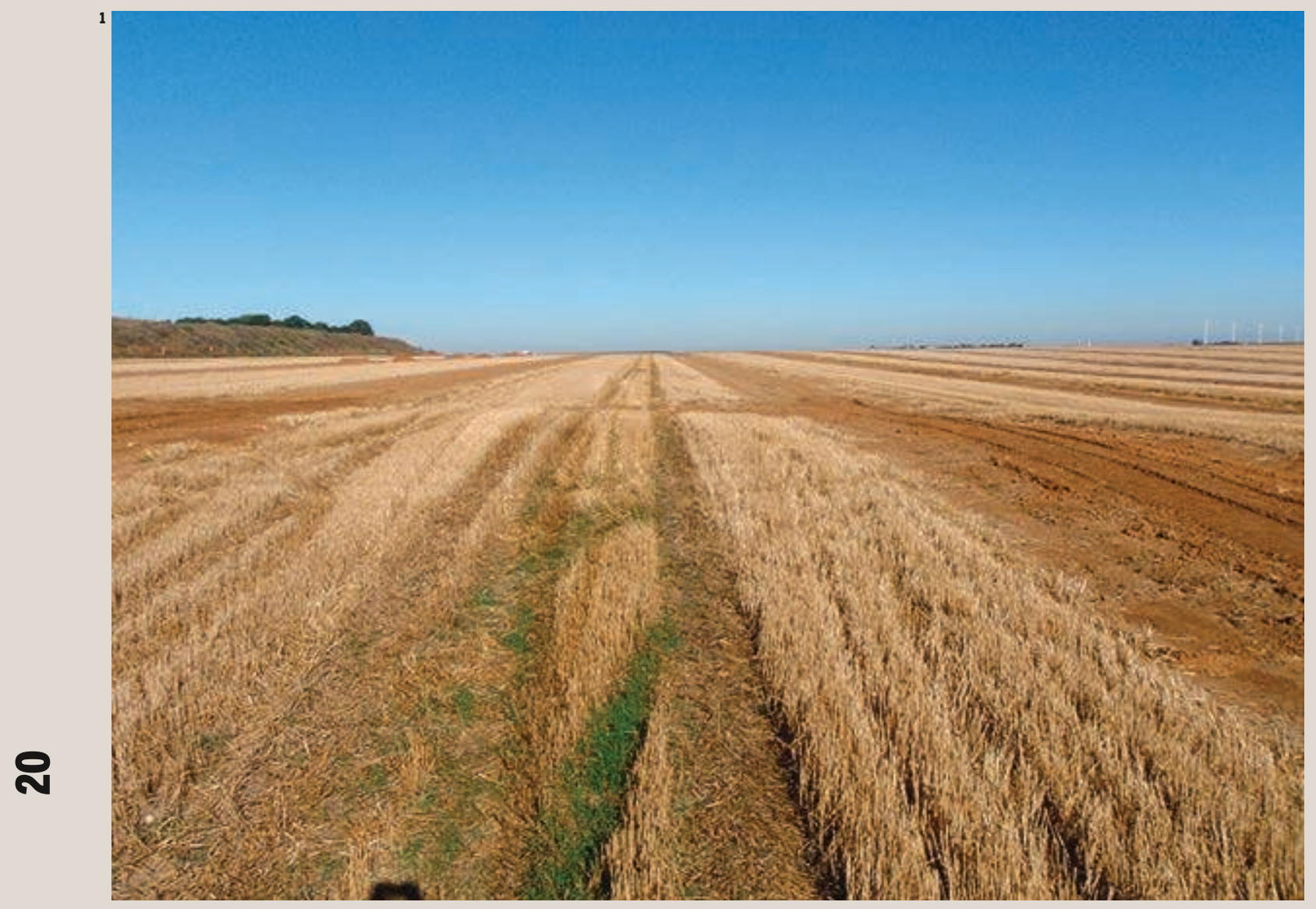

\section{Constructions} néolithiques en terre dans le Bassin parisien

\author{
Tony Hamon Inrap, UMR 8215 « Trajectoires »
}

1. Fouilles du Muid de

Pérollet menées sous

la direction de J.-P. Gay,

Inrap.
Le site du Petit Perollet, découvert lors d'un diagnostic mené par l'Inrap sur la commune de Villeneuve-sur-Conie (Loiret) ${ }^{1}$ (Gay, 2013), est implanté sur une crête située à l'interfluve de deux vallées sèches d'environ cinq mètres de profondeur pour cinquante à cent mètres de largeur. Il est surtout localisé sur la crête et le versant sud d'une des deux vallées. Il se signale dans le paysage par une butte de moins de $1,5 \mathrm{~m}$ de hauteur et s'étend sur une surface estimée de près d'un hectare [ill. 1] ; il semble qu'il soit entièrement compris dans l'emprise. D'après le mobilier récolté lors du diagnostic, il s'agit d'un site du Néolithique moyen ( $\mathrm{Iv}^{\mathrm{e}}$ millénaire avant notre ère).

La visite du site au moment de l'intervention, les relevés de terrain en plan et les clichés photographiques des coupes ont permis d'identifier deux phases de constructions en terre. Le niveau le plus ancien paraît avoir entièrement brûlé - c'est ce que laisse supposer la paroi externe rubéfiée sur une épaisseur d'environ $1 \mathrm{~cm}$ des bâtiments qui ont été reconnus.

Identifiés dans un premier temps comme de la céramique dispersée sur le terrain, ces éléments ont été relevés en plan. Un sondage manuel réalisé dans une tranchée [ill. 2] a permis de reconnaître les murs de deux bâtiments. Il s'agit de murs pignons (abside) prolongés chacun par un mur gouttereau. Lors du sondage manuel, les murs gouttereaux ont été fouillés par moitié depuis l'intérieur, tandis que les pignons ont seulement été sondés. Le sol intérieur n'a pas pu être atteint. Par ailleurs, trois assises de pains de terre massive au matériau épuré ont pu être observées en coupe [ill. 2]. Un autre bâtiment a également été identifié par des restes de murs visibles en décapage, à l'arrière de ces premiers éléments. En l'état, trois bâtiments au moins ont été reconnus pour la phase ancienne.

Le niveau le plus récent présente des informations plus liminaires. En coupe, des pains de terre massive non brûlés ont été identifiés. Ce second niveau d'occupation a été en partie érodé par les labours modernes [ill. 3].

D'après l'étude céramique (Gay, 2013), le mobilier, homogène, est attribué à la période 3 du Néolithique moyen entre 3900 et 3600 avant notre ère. Il s'agit donc actuellement d'une des plus anciennes traces de construction en terre massive néolithique dans le Bassin parisien. Par ailleurs, le niveau le plus ancien a livré des éléments sur l'architecture des bâtiments. Ainsi, suivant le sondage réalisé dans une des tranchées, les bâtiments comporteraient des croupes tandis que, sur d'autres relevés, des angles droits semblent se dessiner. Il se pourrait donc que, comme sur le site du Néolithique moyen de Lillemer (Ille-et-Vilaine) [encadré 2 p. 22], les bâtiments de Villeneuve-sur-Conie comportent un pignon droit et une 

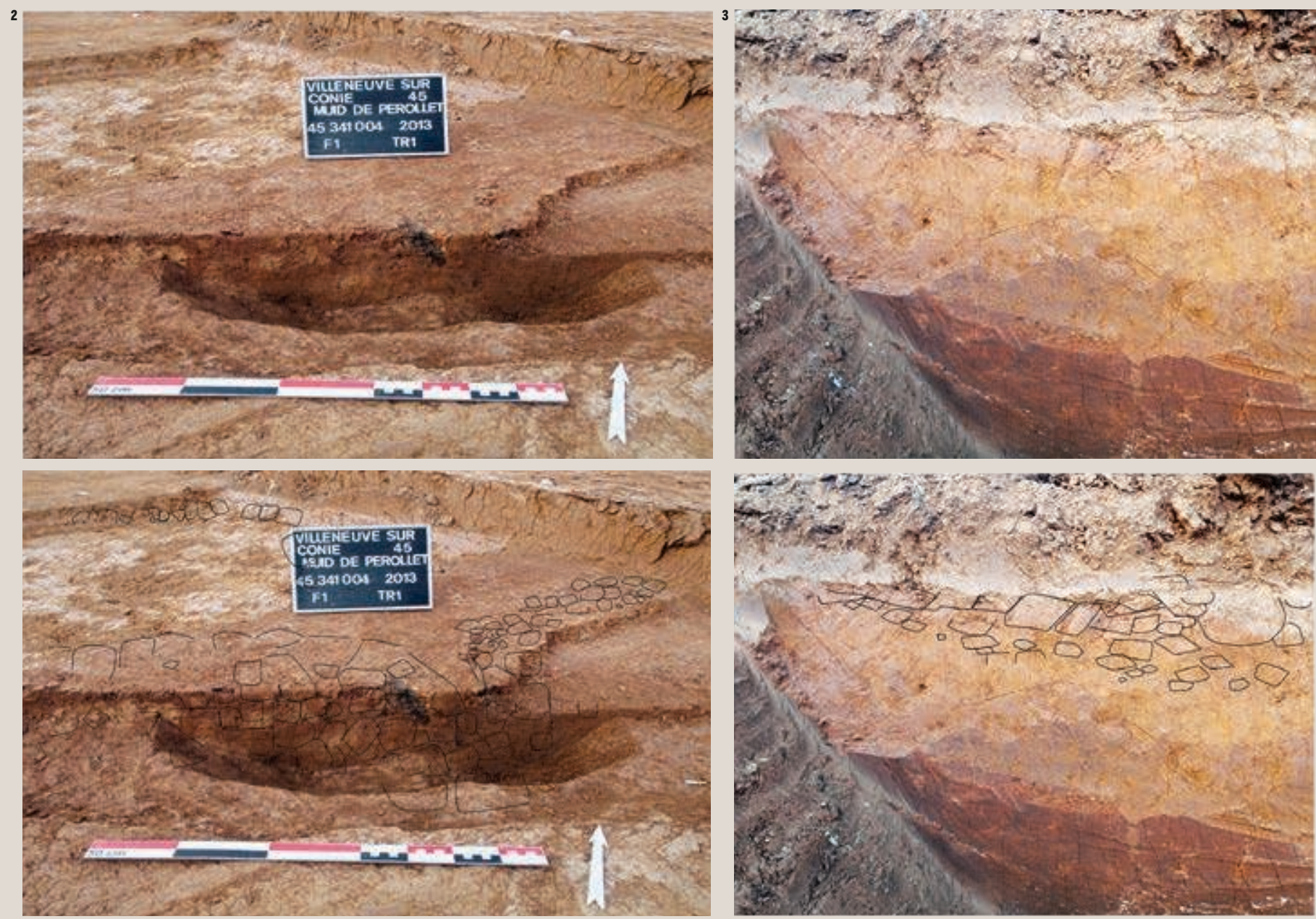

2. Tranchée 1-F1, vue en

plongée du sud, de deux

bâtiments en terre

partiellement dégagés et

sondés manuellement. Les

parements extérieurs ont

semble-il brûlé, ce qui

expliquerait la présence de

ces éléments rubéfiés. Les

deux bâtiments semblent

séparés par une rigole.Au

second plan, un troisième

bâtiment en coupe.

croupe. Cependant, à la différence de Lillemer, il ne s'agit pas d'un site de hauteur et il n'a pas été reconnu lors du diagnostic de limite matérialisant la périphérie du site. D'un point de vue méthodologique, enfin, le niveau incendié a offert la possibilité de dégager des éléments de bâtiments dans de bonnes conditions de visibilité, ce qui est rare.

On peut donc regretter que le diagnostic n'ait pas été suivi d'une prescription de fouille qui aurait permis d'approfondir nos connaissances sur ce site. À

l'exemple de celui de Prasville, on ne peut que souhaiter que des interventions d'équipes pluridisciplinaires au fait du sujet se multiplient et que ces découvertes s'accroissant, cela conduise à la reconnaissance de ce type de sites dès le diagnostic.
3. Tranchée 7, détail de la stratigraphie dans ce secteur du site.Au moins trois niveaux de pains de terre sont visibles dans la coupe. De forme quadrangulaire, les modules sont variés. L'inclinaison de l'ensemble pourrait correspondre à l'effondrement d'un mur de terre à l'intérieur d'un bâtiment. Le substrat n'ayant pas été atteint à cet endroit, il n'est pas possible de dire si le site est install sur le substrat calcaire.
Références bibliographiques

GAY J.-P. (DIR.), 2013, Loiret (45), Villeneuve-sur-Conie, «le Muid de Pérollet », Rapport d'opération, Inrap-SRA Centre, 118 p. 
1. Des niveaux de sols étagés et des vestiges de constructions en terre, conservés en élévation, ont été mis au jour à Lillemer sous la masse du talus du Néolithique moyen.

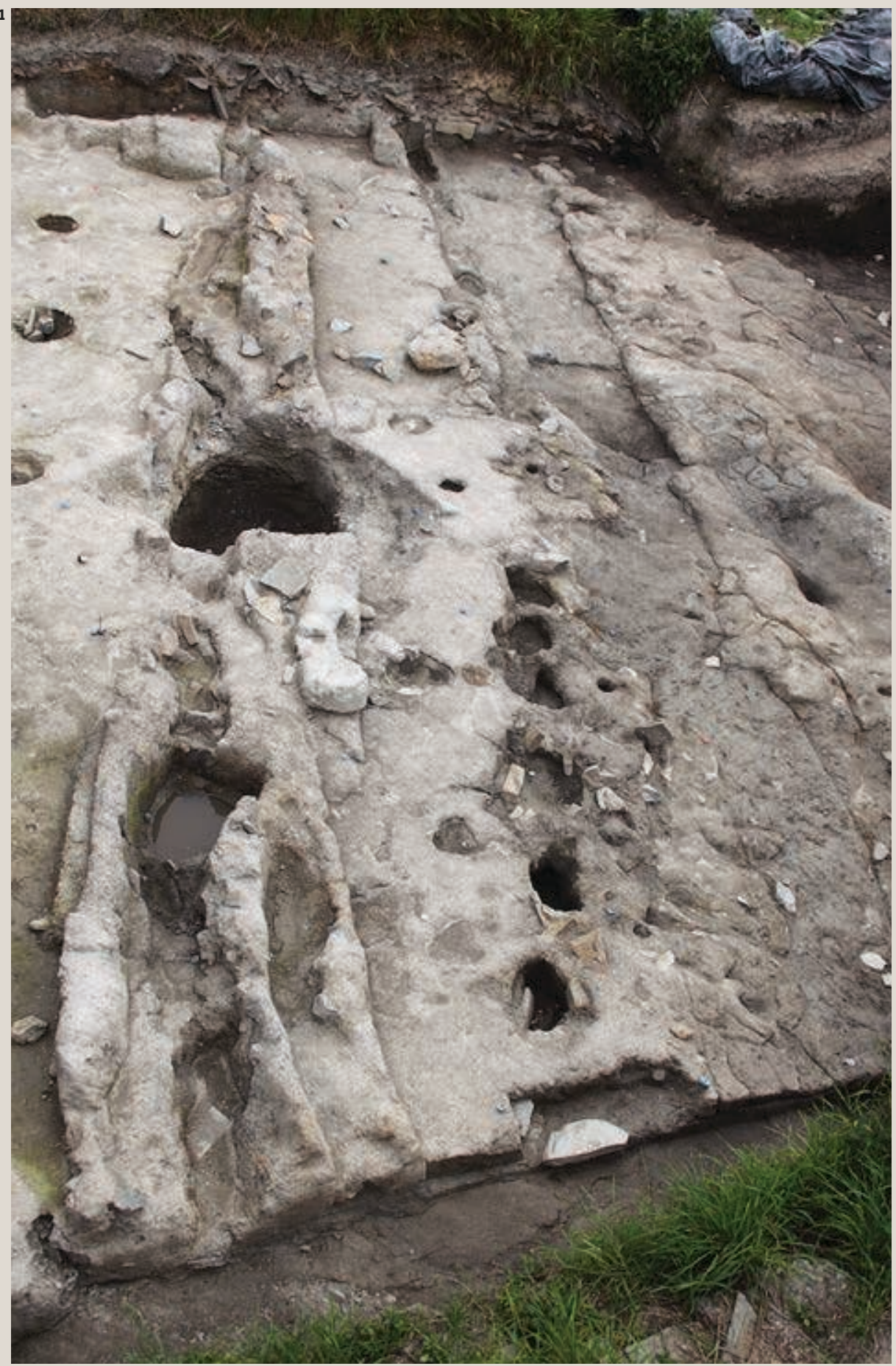

À Lillemer (Ille-et-Vilaine), au fond de la baie du Mont-Saint-Michel, les vestiges d'une architecture en terre néolithique ont dernièrement été mis en évidence (Laporte et al., 2015) [ill. 1]. Il s'agit de bâtiments aux murs construits à base de terre crue, sans armature de bois, préludant aux aménagements d'une vaste enceinte du Néolithique moyen, au cours de la seconde moitié du $v^{\mathrm{e}}$ millénaire avant notre ère. Celle-ci cerne l'ensemble d'une butte rocheuse qui émerge des marais environnants, riches également de vestiges appartenant à cette période. La mise en évidence de constructions en terre est d'abord passée par l'identification de fragments isolés de pains de terre cuite par un incendie, puis d'autres en terre crue. Un parement de mur a été rendu identifiable par son contact vertical avec des niveaux incendiés et effondrés. Un autre niveau de lecture correspond à la prise en compte d'épais bourrelets d'argile, lors de la recherche des murs. Une étude micromorphologique a permis d'identifier la terre massive comme technique constructive, notamment sous la forme d'éléments modulaires mis en place par façonnage direct et préparés à partir de limons et de graviers issus des sols environnants ou des formations palustres [ill. 2]. La fouille des vestiges 


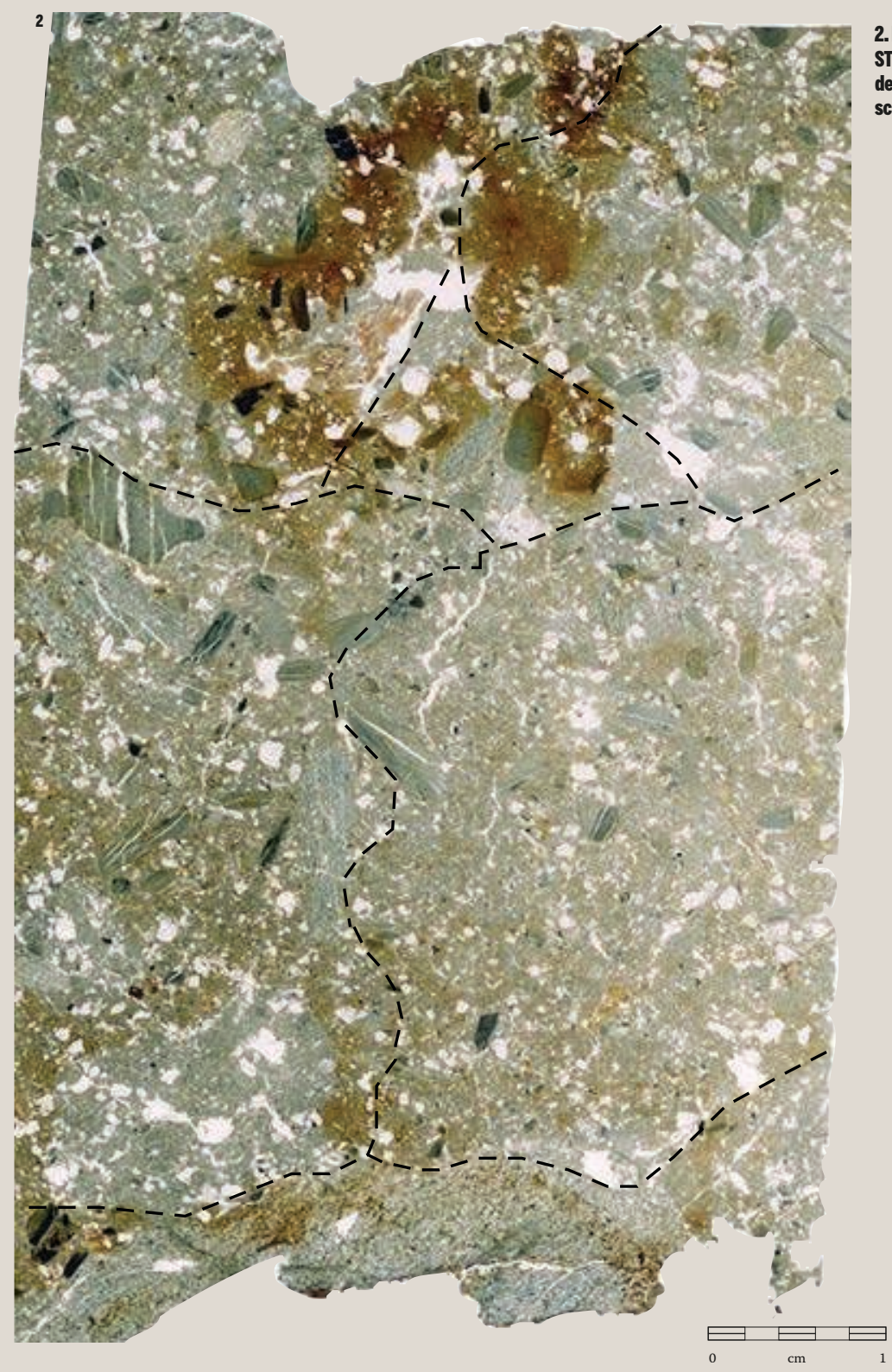

terre crue avaient déjà été observés en différents points de la butte de Lillemer lors de sondages et fouilles, tant programmées que préventives (BizienJaglin et al., 2010 ; Laporte et al., 2014). Sur le flanc sud de la butte, une épaisse couche argileuse contenant des artefacts néolithiques a été dégagée, avant la mise en évidence de fronts de taille résultant de la construction de terrasses étagées.

L'épaisseur de cet horizon et la restitution des reliefs rocheux originaux orientent vers des apports anthropiques importants. Cette hypothèse a également été confirmée par les analyses micromorphologiques. Un peu plus bas sur cette pente, une coupe montrait une forme rectangulaire évoquant une possible élévation de terre construite. Au nord de la butte, le rempart observé en coupe est entièrement constitué de ces mêmes matériaux, recouvrant là aussi des reliefs antérieurs en argile. L'ensemble de ces observations montre que les constructions étudiées dans la parcelle 733 (qui recoupe le tracé du talus), sur une superficie de seulement $150 \mathrm{~m}^{2}$, ne constituent pas des éléments isolés. Flles résultent d'énormes investissements humains, à l'image de ce que suggérait déjà l'aménagement de terrasses sur les flancs de la butte ou, plus tard encore, l'édification d'un talus périphérique ceinturant l'ensemble de la butte rocheuse sur plus d'un kilomètre linéaire. Ces fouilles ont aussi contribué à attirer l'attention - jusque sur les rives de la Manche et pour une période aussi ancienne que le Néolithique moyen - sur une matière omniprésente sur les chantiers de fouilles, l'argile, que tout le monde sait implicitement avoir été largement utilisée pendant les périodes anciennes, sans toujours penser à mettre en évidence son usage comme matériau de construction. dégagement des sols se sont effectués au détriment des masses argileuses intercalées (murs effondrés, recharges successives de sol et/ou possibles éléments construits), tant la lecture de ce sédiment à première vue très homogène s'est avérée complexe. L'une des constructions mises au jour, large de $2,50 \mathrm{~m}$ à l'intérieur et longue d'au moins $9 \mathrm{~m}$, est délimitée par deux murs latéraux - nord et sud-larges de $1,20 \mathrm{~m}$, un mur de refend à l'est apparemment de moindre puissance, un sol et quatre fosses d'implantation de poteaux suivant un axe décentré. Le mobilier y est particulièrement rare. On note l'absence de foyer. Des poutres de bois rubéfiées et des dalles de schiste brûlées témoignent, en lien avec les trous de poteau, d'une couverture - sans doute végétale-maintenue avec des dalles et soutenue par une charpente en bois. Au sud et légèrement en contrebas, un deuxième niveau de sol conservé sur une plus faible superficie a été percé par les aménagements nécessaires à la mise en place, postérieure, d'une forte palissade. Ce sol ne porte pas les altérations propres à un espace ouvert. ígalement constitué de pains de terre, c'est-à-dire bâti, il présente les mêmes qualités que celui, interne, du bâtiment précédemment décrit. Plus au sud encore, un massif de $2,5 \mathrm{~m}$ de largeur est parallèle aux deux murs déjà mentionnés. Différentes natures de sédiments mis en œuvre, de même que les témoins de murs antérieurs repris, ou arasés, montrent l'existence de plusieurs états successifs. Le plan de ces constructions se rapproche de celui, aggloméré, d'un village plutôt que de celui des grands bâtiments sur poteaux porteurs habituellement connus pour cette période dans cette régions. Rétrospectivement, les témoins d'aménagements similaires utilisant la
Références bibliographiques

BIZIEN-JAGLIN C, GUYODO J.-N., LAPORTE L, 2010, «Occupation du Néolithique moyen autour de la butte de Lillemer (Ille-et-Vilaine) », Archéo-Théma, 101, septembre 2010, p. 26-34.

LAPORTE L., BIZIEN-JAgLIN C. GUYODO J.N., 2014 «Enceintes néolithiques de louest de la France : une archéologie des fossés? ?, in Joussaume R., LARGE J.-M. (ÉD.), Enceintes néolithiques de l'ouest de la France, de la Seine à la Gironde, Actes du Colloque CrabeNéo, sept. 2012, Quimper, Association des Publications Chauvinoises, p. 455-488.

LAPORTE L., BIZIEN-JAGLIN C., WATTEZ J. et al., 2015 « Another brick in the wall: fifth millennium $B C$ earthen-walled architecture on the Channel shores ", Antiquity, 89, 346, p. 80o-817. 


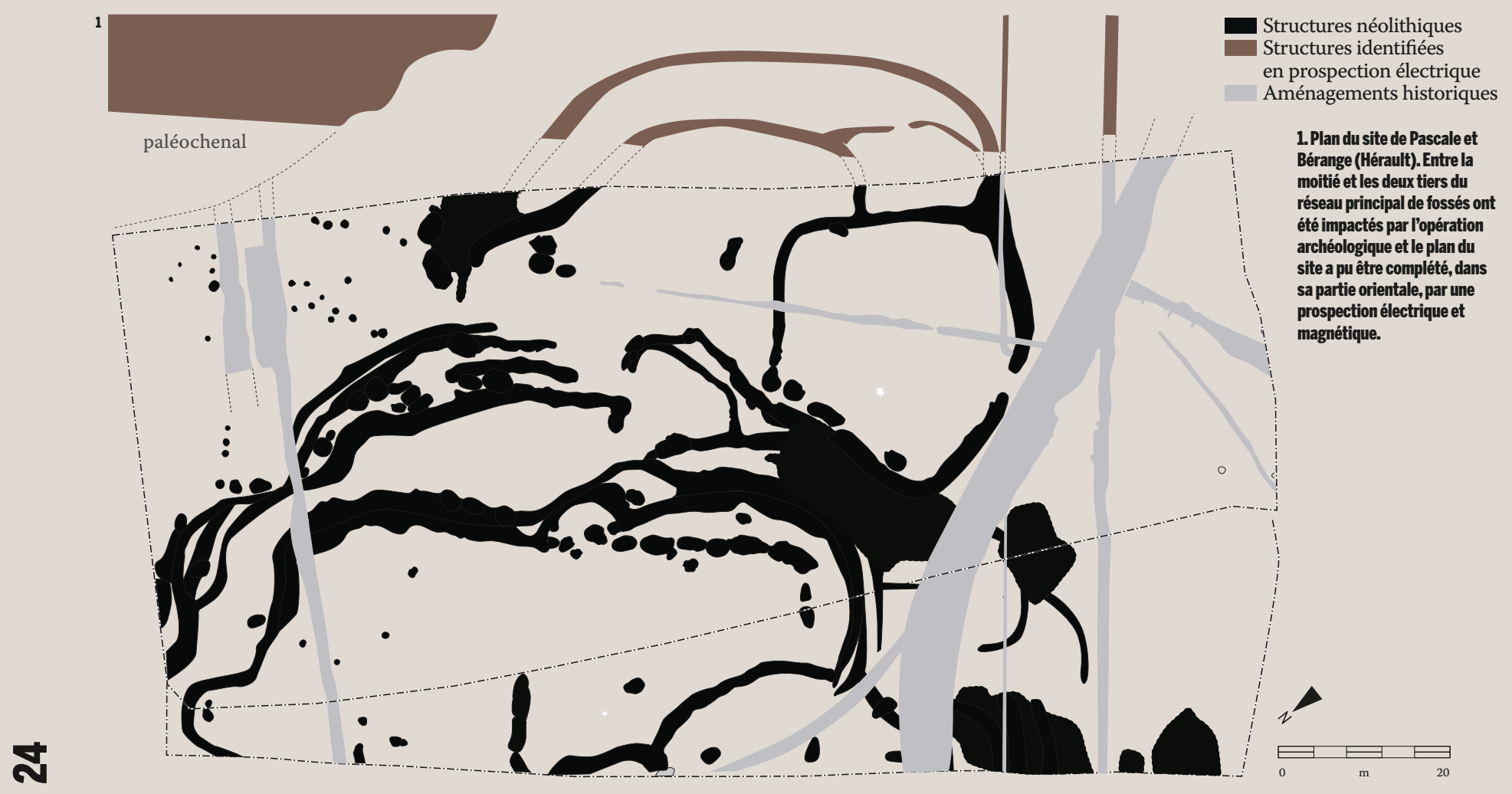

\section{I'utilisation}

de la terre

architecturale

à Pascale et Bérange

Muriel Gandelin Inrap, UMR 5608 « Traces »
1. Fouille menée de juillet 2013 à février 2014 sous la direction de Muriel Gandelin, Inrap.
Des fouilles menées sur une vaste zone de $16000 \mathrm{~m}^{2}$, située aux lieux-dits Pascale et Bérange, à cheval sur les communes de Saint-Brès et Mudaison ${ }^{1}$ (Hérault), ont révélé des vestiges se rapportant à une occupation du Néolithique final (culture de Fontbouisse) assez dense, située en bordure de cours d'eau. Les niveaux de sol de cette époque ont été détruits par les travaux agricoles et l'essentiel des découvertes consiste en un réseau de structures fossoyées qui marquent la succession d'occupations retranchées [ill. 1]. La surface totale ceinturée peut être estimée entre un hectare et demi et deux hectares. Au final, les vestiges mis au jour correspondent à plusieurs enceintes successives, matérialisées au sol par des fossés au développement curviligne

- dont la forme suggère l'existence de bastions - et par de profondes tranchées de palissades dont certaines aménagent des entrées en pince de crabe. La variété et la nature des vestiges mobiliers découverts sur l'ensemble du site - abondante céramique et industrie lithique en silex, industrie en os ou en cuivre, macro-outillage et rejets alimentaires - évoquent les vestiges habituellement découverts en contexte d'habitat et laissent penser que ces différentes occupations correspondent à autant d'installations villageoises successives.

Parmi les autres structures découvertes, plusieurs chapelets de creusements allongés, parfois coalescents, semblent suivre le développement des fossés. Ces éléments correspondent à des fosses d'extraction et de préparation de la terre à bâtir destinée à l'édification des élévations des enceintes dont il est difficile de préciser l'architecture. Une partie de la terre utilisée pour ces constructions se trouve remobilisée dans le comblement des fossés, au sein de niveaux pouvant dépasser plusieurs centimètres d'amplitude. Ces vestiges, qui sont les seuls témoins des élévations, se présentent sous plusieurs formes qui peuvent se définir en fonction de leur degré d'ustion. Deux grandes catégories peuvent ainsi être distinguées : la terre crue non chauffée et la terre crue ayant subi l'action du feu à des degrés divers. Dans le cas des éléments ayant subi l'action du feu, le caractère souvent fortuit de la chauffe explique la variabilité observée dans la couleur, la plasticité et l'état de conservation des différents produits découverts [ill. 2, a.]. La préparation du matériau (l'homogénéisation par malaxage et/ou la présence naturelle ou l'adjonction volontaire d'éléments non plastiques, minéraux ou organiques, à l'argile) a également une influence directe sur les caractéristiques physico-chimiques des produits obtenus et ces éléments ajoutés peuvent agir comme fondant et/ou comme dégraissant. Dans certains cas, la structure du matériau n'a pas été durablement modifiée par la chauffe ; l'eau interstitielle n'a pas été éliminée des feuillets d'argile : les produits sont fragiles et peuvent reprendre leur plasticité après humidification. Dans d'autre cas, la chauffe a été suffisamment importante pour que l'eau de constitution de l'argile ait été éliminée et que sa 

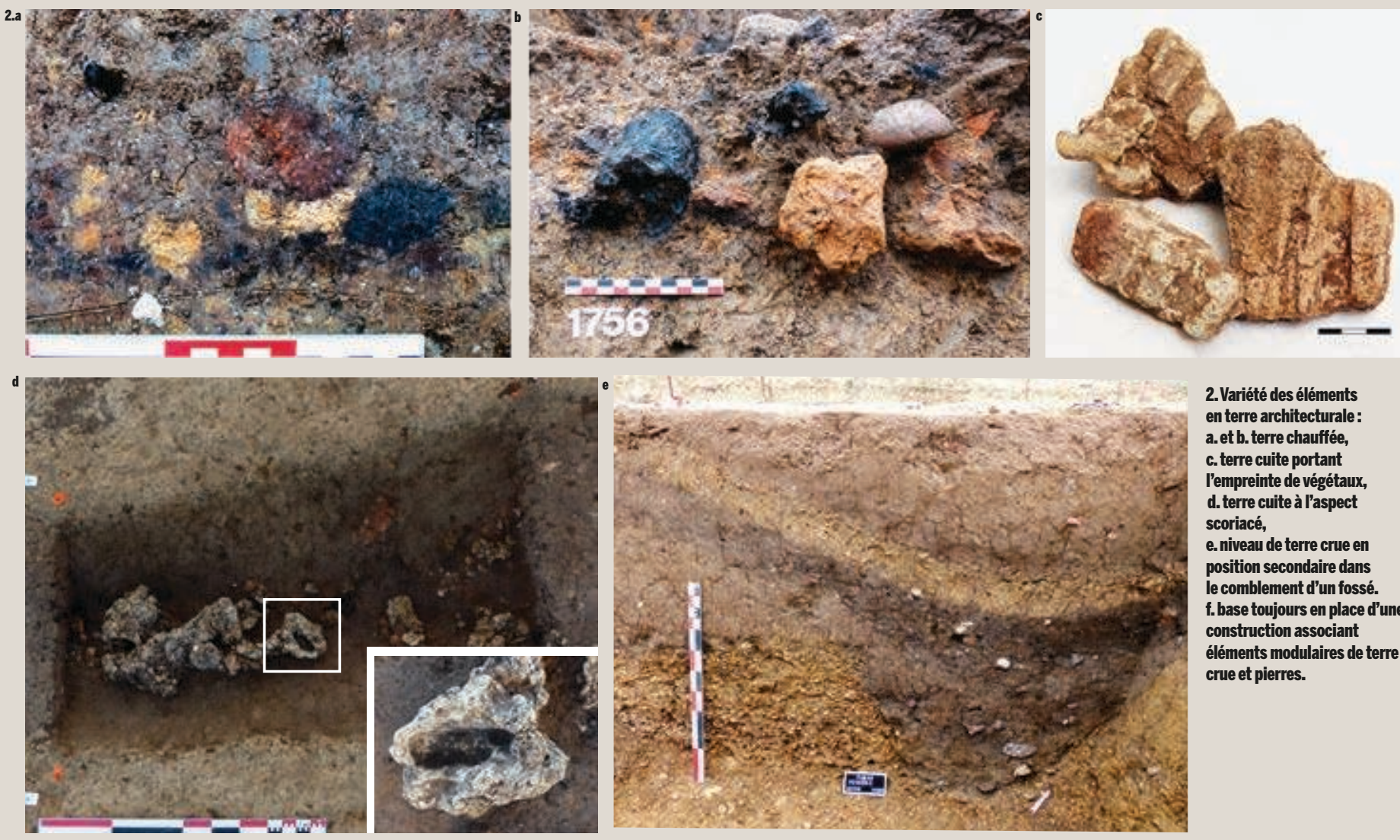

2. Variété des éléments en terre architecturale : a. et b. terre chauffée, c. terre cuite portant l'empreinte de végétaux, d. terre cuite à l'aspect scoriacé, e. niveau de terre crue en position secondaire dans le comblement d'un fossé. f. base toujours en place d'une construction associant éléments modulaires de terre crue et pierres.

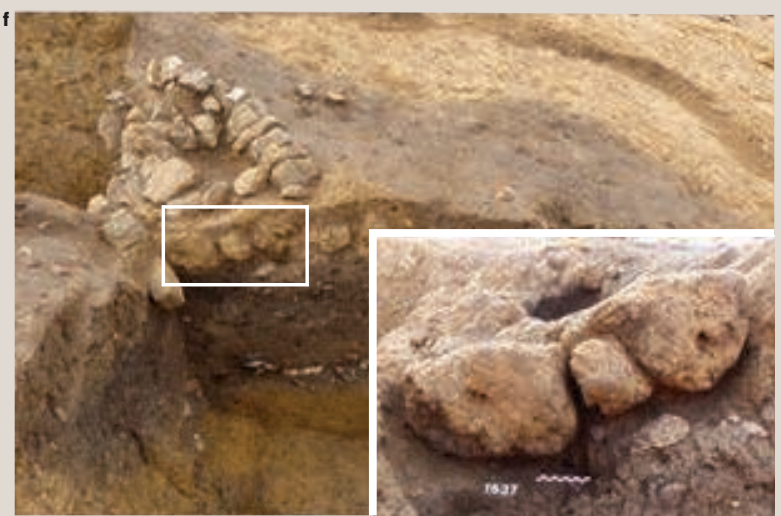

structure ait été irrémédiablement détruite : les éléments qui en résultent s'apparentent alors à de la céramique [ill. 2, b.]. Ces fragments accidentellement cuits sont souvent les seuls à conserver des surfaces portant des empreintes interprétables [ill. 2, c.].Il a ainsi été possible de préciser que la terre était, à Pascale et Bérange, souvent plaquée contre des végétaux souples dont le diamètre excède rarement $1,5 \mathrm{~cm}$. Quelques branches de petit module (5 à $10 \mathrm{~cm}$ ) participaient également à l'armature des constructions. Enfin, en cas de chauffe extrême, les grains de silice présents dans la terre à bâtir ont atteint leur point de fusion et le matériau a eu tendance à se vitrifier à des degrés divers, il présente alors un aspect scoriacé, plus ou moins bulleux [ill. 2, d.]. Dans le cas de la terre à bâtir non chauffée, l'altération subie par le matériau est principalement d'ordre taphonomique et sa conservation est plus aléatoire. La reconnaissance à l'œil nu en est aussi plus difficile. Sur le site de Pascale et Bérange, l'identification de niveaux massifs de terre malaxée, d'une couleur proche du substrat encaissant mais d'une texture fortement homogénéisée, n'a toutefois pas posé de problème [ill. 2 , e.]. Dans de rares cas, la forme du matériau initial a pu être retrouvée. Il peut s'agit de pain ou de boule de terre crue de modules variés ; 1'utilisation de bauge est également probable mais est plus difficile à identifier.

Une des spécificités du site réside dans la dernière forme architecturale documentée, qui est matérialisée par plusieurs bases de murs. Ces vestiges sont postérieurs au réseau de fossés et palissades et sont installés au sommet de leur comblement. Ils paraissent correspondre aux soubassements massifs et soignés de constructions fortement arasées mais dont le développement semble reprendre, au moins en partie, celui des systèmes fossoyés. Un des éléments les plus remarquables consiste en l'association de la terre et de la pierre dans ces constructions. La terre peut être employée à la façon d'un mortier, pour combler les joints ou bien dans des organisations plus complexes, à l'image de cette base d'architecture constituée d'un premier niveau aménagé par des pains de terre de gros module sur lesquels a été soigneusement installée une assise de pierres [ill. 2, f]. La contemporanéité des deux niveaux semble confortée par la présence d'un unique trou de poteau qui traverse la construction sur toute son épaisseur. Cet exemple, remarquablement conservé, reste un témoin exceptionnel de ce type d'architecture mixte. 


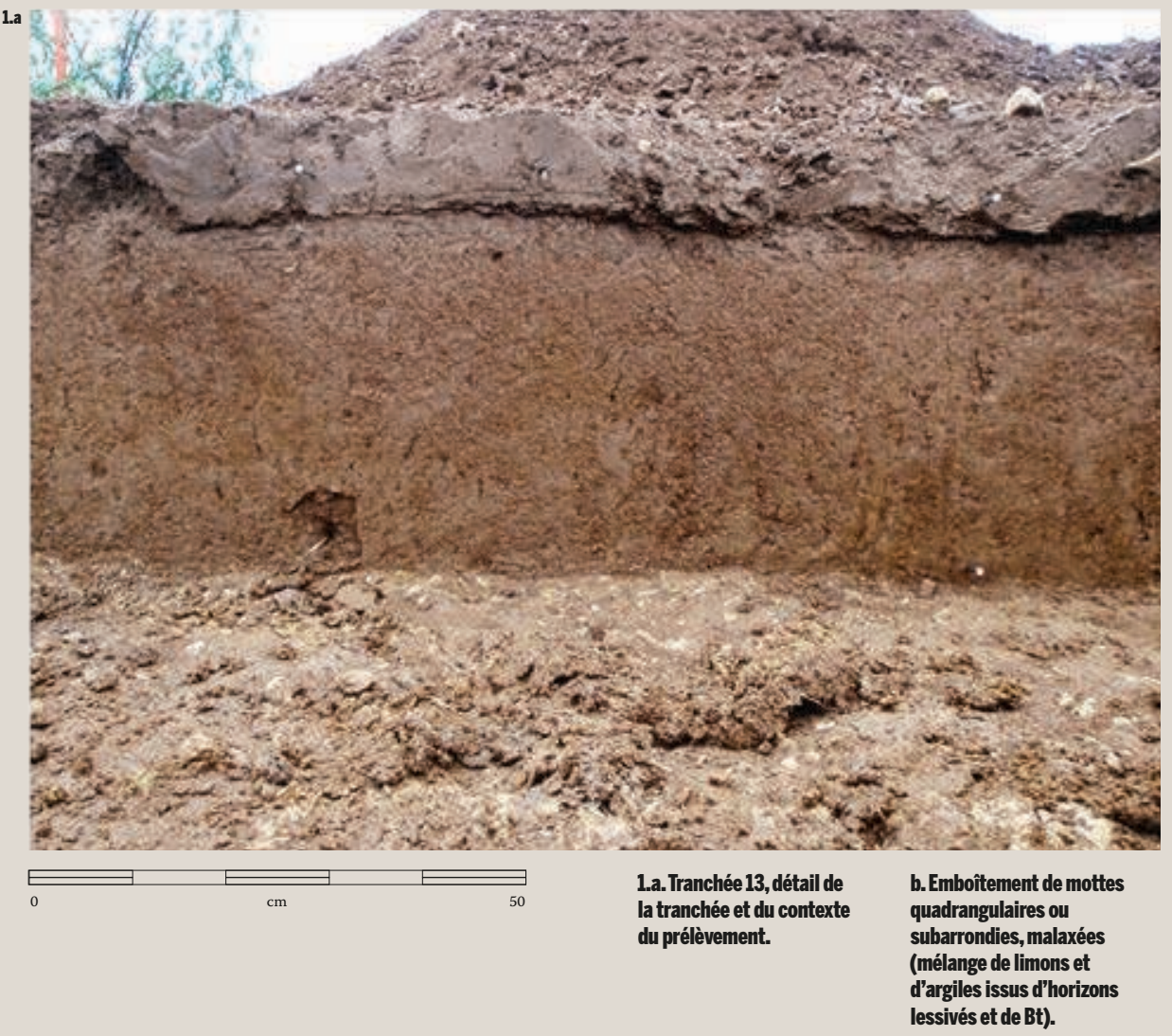

L'habitat stratifié de Prasville (III millénaire)

Annette Bailleux Inrap

Grégoire Bailleux Inrap

Tony Hamon Inrap, UMR 8215 " Trajectoires "

Céline Coussot

Inrap, UMR 8591 «Laboratoire de Géographie Physique » Julia Wattez

Inrap, UMR 5140 "Archéologie des sociétés méditerranéennes »

1. Diagnostic réalisé en

deux tranches, en 2013 et

en 2014, sous la direction

d'Annette Bailleux, Inrap.

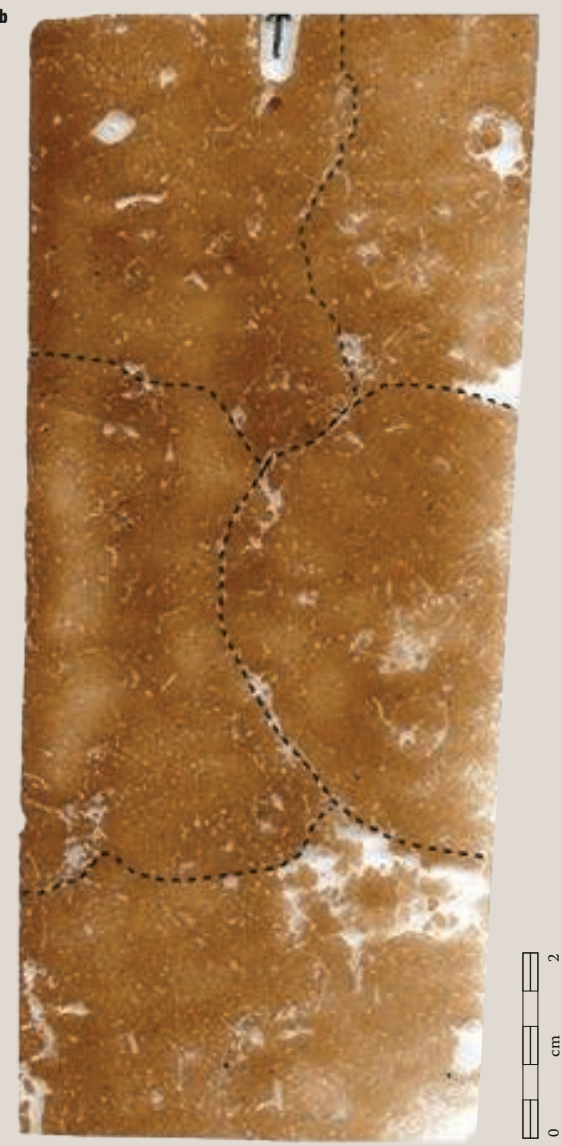

chacune de ces phases. Ils sont tous élevés en terre massive. Les investigations n'ont permis de caractériser que les phases 1 et 2 au centre du site, qui couvre environ 5 hectares. Les matériaux sont distincts selon chacune des phases ou même peut-être selon le secteur géographique du site. In effet, dans le premier secteur diagnostiqué, la terre employée est jaune clair et pourrait se rapporter au Néolithique récent ; dans le second secteur, les matériaux employés sont bruns au centre du site et dans certains cas, brun gris foncé. Pour la phase attribuée au Campaniforme, un seul bâtiment a été observé. Il était perturbé par les labours. Des pierres, extraites du substrat calcaire (du sous-sol), sont employées dans la construction des murs durant cette phase.

Suivant les observations faites en stratigraphie, le sol est décapé jusqu'au substrat calcaire ; les méplats sont bouchés avec des blocs de terre et un radier de terre afin d'aplanir le substrat décapé. Les murs sont construits en terre massive, soit à l'aide de boules de terre, soit à l'aide de modules en forme de pavés, de tailles différentes, souvent non calibrés et de nature composite. Ils sont façonnés par modelage, à partir de sédiments limono-argileux [ill. 1]. Le cœur du mur peut atteindre plus d' $1 \mathrm{~m}$ de largeur. Les sols intérieurs sont matérialisés par un niveau de blocs de terre quadrangulaires de $4 \mathrm{~cm}$ de côté 

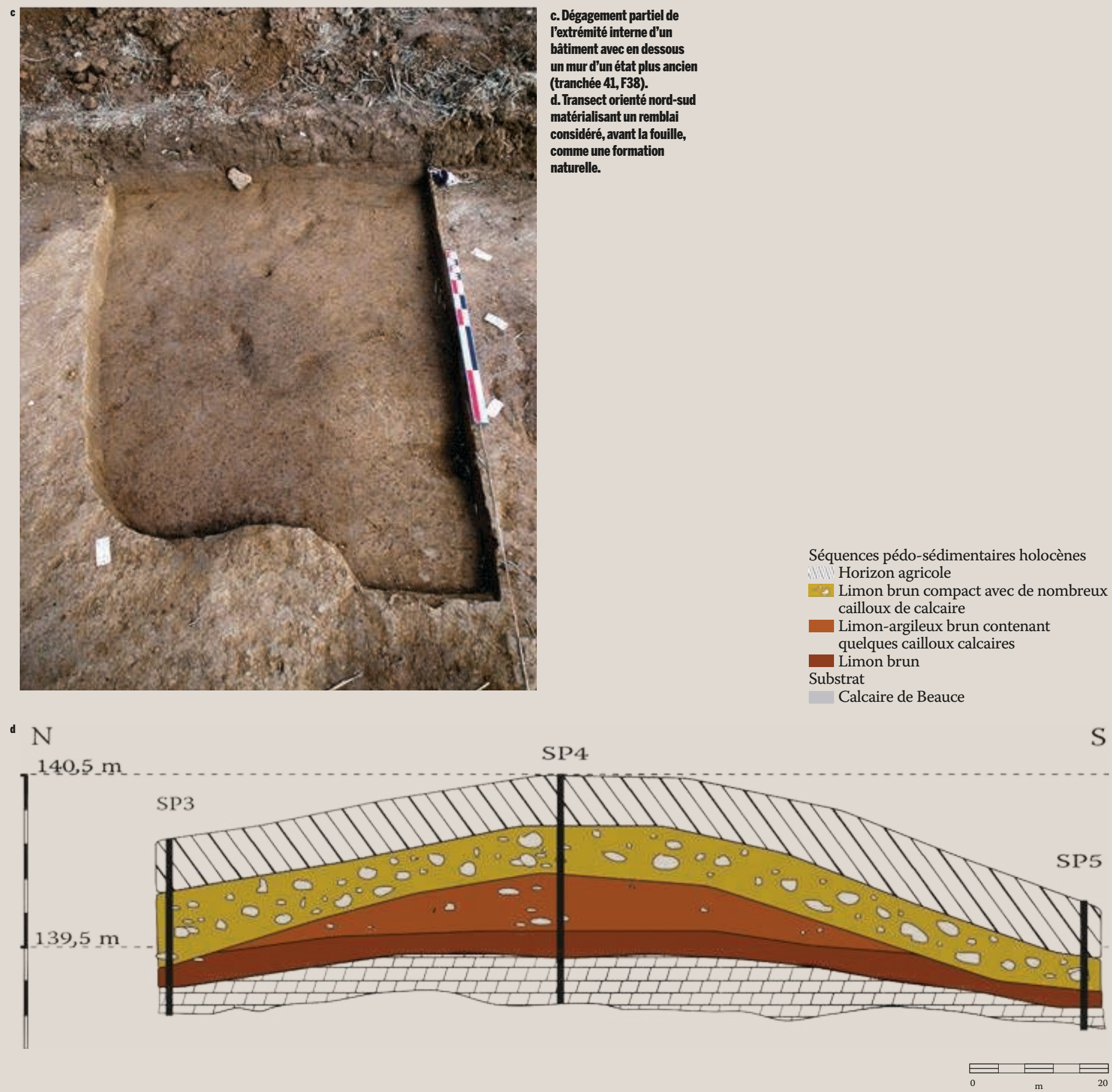

Ils sont construits en alternance avec le rechapage interne des murs. Quatre phases de réfection ou de reconstruction ont été perçues. Les bâtiments sont comblés par la démolition des murs, ces derniers étant conservés sur un peu plus de $50 \mathrm{~cm}$ de hauteur.

Un second niveau de bâtiments recouvre ce premier état du site, il est arasé par les labours.

Ce site a été identifié comme une séquence d'occupation caractérisée par des constructions en terre des $\mathrm{rv}^{\mathrm{e}}$ et $\mathrm{III}^{\mathrm{e}}$ millénaires. On doit en grande partie leur identification à la détection d'anomalies stratigraphiques pouvant correspondre à des restes d'architecture en terre crue, qui a conduit à renforcer l'équipe de diagnostic, notamment au cours de la seconde tranche, avec des archéologues et géoarchéologues sensibilisés à la reconnaissance des vestiges de la construction en terre néolithiques (Bailleux et al., 2015). Ainsi, il a été possible de préciser l'extension spatiale des occupations et les phases architecturales et d'évaluer la diversité des techniques constructives.

\section{Références bibliographiques}

Bailleux A., Bailleux G., Coussot C., Creusillet M.-F, Hamon T., Vaille V., Wattez J., Wedajo B., 2014 Eure-et-Loir (28), Prasville, " la Fosse Blanche»,

Rapport d'opération, Inrap-SRA Centre-Val de Loire, $193 \mathrm{P}$

Bailleux, G., Bailleux A., Coussot C., Hamon T., Lethrosne H., Wattez J., 2015, Prasville (Eure-etLoir), la Fosse Blanche - tranche 3. Habitat stratifié en terre crue au Néolithique final en Beauce, Rapport d'opération, Inrap, SRA Centre Centre-Val de Loire, $277 \mathrm{p}$

IrRIBARRIA R., HAMON T., 2006, « Un nouveau groupe du III ${ }^{e}$ millénaire en Loire moyenne à Suèvres "les Sables” (Loir-et-Cher) », Internéo, 7, p. 131-141. 